\title{
Rosin-Based Epoxy Vitrimers with Dynamic Boronic Ester Bonds
}

\author{
Yanning Zeng *, Jiawei Li, Shuxin Liu and Bin Yang
}

Citation: Zeng, Y.; Li, J.; Liu, S.; Yang, B. Rosin-Based Epoxy Vitrimers with Dynamic Boronic Ester Bonds. Polymers 2021, 13, 3386. https:// doi.org/10.3390/polym13193386

Academic Editors: Sixun Zheng and Rentong Yu

Received: 1 September 2021

Accepted: 29 September 2021

Published: 1 October 2021

Publisher's Note: MDPI stays neutral with regard to jurisdictional claims in published maps and institutional affiliations.

Copyright: (c) 2021 by the authors. Licensee MDPI, Basel, Switzerland. This article is an open access article distributed under the terms and conditions of the Creative Commons Attribution (CC BY) license (https:// creativecommons.org/licenses/by/ $4.0 /)$.
Key Laboratory of New Processing Technology for Nonferrous Metal and Materials (Ministry of Education), College of Material Science and Engineering, Guilin University of Technology, Guilin 541004, China; zjljw1998@163.com (J.L.); liushuxin@126.com (S.L.); a18832111836@163.com (B.Y.)

* Correspondence: ynzeng@glut.edu.cn

\begin{abstract}
Rosin is an abundantly available natural product. In this paper, for the first time, a rosin derivative is employed as the main monomer for preparation of epoxy vitrimers to improve the mechanical properties of vitrimers. Novel epoxy vitrimer networks with dynamic reversible covalent boronic ester bonds are constructed by a reaction between thiols in 2,2'-(1,4-phenylene)-bis (4-mercaptan-1,3,2-dioxaborolane) (BDB) as a curing agent and epoxy groups in the rosin derivative. The rosin-based epoxy vitrimer networks are fully characterized by Fourier transform infrared spectroscopy (FTIR), an equilibrium swelling experiment, and dynamic mechanical analysis (DMA). The obtained rosin-based epoxy vitrimers possess superior thermostability and good mechanical properties. Due to transesterification of boronic ester bonds, rosin epoxy vitrimer network topologies can be altered, giving welding, recycle, self-healing, and shape memory abilities to the fabricated polymer. Besides, the effects of treating time and temperature on welding capability is investigated, and it is found that the welding efficiency of the 20\% C-FPAE sample is $>93 \%$ after treatment for $12 \mathrm{~h}$ at $160{ }^{\circ} \mathrm{C}$. Moreover, through a hot press, the pulverized samples of $20 \% \mathrm{C}$-FPAE can be reshaped several times and most mechanical properties are restored after reprocessing at $200{ }^{\circ} \mathrm{C}$ for $60 \mathrm{~min}$. Finally, chemical degradation is researched for the rosin-based epoxy vitrimers.
\end{abstract}

Keywords: rosin; vitrimer; reprocessing; self-healing

\section{Introduction}

Thermosetting polymers that originate from petroleum chemicals have been involved in many industrial applications, such as protective coatings, wind turbines, highperformance materials for aircrafts, and other areas, because of their dimensional stability, mechanical properties, and creep/chemical resistance [1]. However, the inherent irreversible cross-linking naturally restricts their flow and they cannot be reshaped, reprocessed, or recycled, leading to an aggravating petroleum resource crisis. To address this issue, dynamic covalent bonds can be incorporated into the thermoset polymer network, giving it the unique features, such as malleability, self-healing, and reprocessing properties. Vitrimers with dynamic covalent bonds flow when heated but remain insoluble [2]. A network of vitrimers can change their topologies without decreasing their connectivity, attributed to associative exchange reactions, which maintain constant the number of chemical bonds and cross-links. Moreover, vitrimers can flow when a stimulus is applied, because associative exchange reactions permit the network topology to fluctuate; furthermore, the kinetics change can control the relaxation dynamics and viscosity of vitrimers [3,4]. At high temperatures, vitrimers can be processed due to fast exchange reactions. At low temperatures, the shape is fixed either by quenching the exchange reactions [5] or by the motion of polymer chains through the glass transition temperature $\left(T_{g}\right)$ or crystallization $[3,6]$. Thus, vitrimers with the desired chemical properties can be reshaped and recycled. The initial epoxy vitrimer network is reorganized via transesterification [2]. Currently, the library of dynamic exchange reactions has expanded to include chemistries such as boronate 
ester exchange [7-9], boroxine exchange [10], dioxaborolane metathesis [8], transamination [11], trans-N-alkylation [12], reversible addition of thiols [13], imine exchange [14], olefin metathesis [15], and transcarbonation [16] Among these chemistries, boronate ester bonds are renowned for their dynamic and robust features and have been widely employed in solution-based systems for molecular sensors [17] and self-healing hydrogels [18]. In contrast, improvements in vitrimer mechanical performance are achieved at the expense of dynamic properties due to restricted chain mobility, and it is a challenge to enhance both mechanical performance and dynamic properties.

Rosin is an abundantly available and low-cost natural product and primarily consists of rosin acids with characteristic hydrophenanthrene structures and $10 \%$ neutral materials. Because of hydrogenated phenanthrene ring, rosin acids have cycloaliphatic structures, giving the features of excellent biodegradability, solubility, and biological compatibility. As a consequence, rosin and its derivatives have served as alternatives to petroleum-based rigid monomers in polymer fabrication [19,20], such as polyurethane [20], polyester [21], and epoxy resins [22,23]. Meanwhile, petroleum-based curing agents such as 1,2-cyclohexanedicarboxylic anhydride (CHDA) and 1,2,4-benzenetricarboxylic anhydride (BTCA) also can be replaced by rosin derivatives $[19,22,24,25]$. It is found that hydrogen phenanthrene ring structures of rosin acids are beneficial for the thermal and mechanical properties of the obtained thermosets. Moreover, $T_{g}$ improvements of the obtained cured acrylated epoxidized soybean oil are significantly influenced by the curing agent of rosinbased derivatives [26], and cured epoxies employing rosin as a curing agent display similar moduli and a higher $T_{g}$ than commercial monocyclic analogues $[19,22]$. Besides, polymers with rosin-based components, such as epoxy resin, polyester, and polyamide, exhibit high thermal stability or high mechanical properties [26,27].

To the best of our knowledge, there is not a similar study using rosin-based derivatives as the main monomer for vitrimer preparation to improve their mechanical properties in the literature. In this work, first, a rigid vitrimer monomer derived from rosin was synthesized, and then 2,2'-(1,4-phenylene)-bis(4-mercaptan-1,3,2-dioxaborolane) (BDB) as a curing agent reacted with the rosin-derived monomer by one-pot thermally initiated thiol-epoxy click chemistry, producing vitrimers with a framework of a rigid hydrogenated phenanthrene ring. The objective of this research is to make use of natural rosin to fabricate biobased vitrimers with high mechanical properties, thermostability, and $T_{g}$. Meanwhile, we studied the fabrication of high-performance vitrimers using rosin resources, for vitrimers naturally have multifunctionality, such as self-healing, shape memory, and reprocessing.

\section{Experimental Section}

\subsection{Materials}

Rosin (acid number $=166 \mathrm{mgKOH} \cdot \mathrm{g}^{-1}$ ) was kindly supplied by Guilin Xingsong Forest Chemical Co., Ltd (Guilin, China). 1-Thioglycerol (99\%), 1,4-phenylenediboronic acid $(97 \%)$, fumaric acid (FA), epichlorohydrin (EC), ethanol (EtOH), acetone, potassium hydroxide $(\mathrm{KOH})$, triethylamine $\left(\mathrm{Et}_{3} \mathrm{~N}\right)$, and 4-dimethylaminopyridine $(99 \%)$ were purchased from Aladdin, Shanghai, China. Tetrahydrofuran (THF), toluene, dichloromethane, $30 \%$ hydrogen peroxide aqueous solution $\left(\mathrm{H}_{2} \mathrm{O}_{2}\right)$, hydrochloric acid $(\mathrm{HCl})$, and magnesium sulfate were purchased from XiLong scientific Co., Ltd (Shantou, China).

\subsection{Synthesis of Fumaropimaric Acid (FPA)}

FPA was synthesized according to a previous work [28]. Briefly, a $500 \mathrm{~mL}$ four-neck round-bottomed flask equipped with a gas tube, a mechanical stirrer, a thermometer, and a $\mathrm{N}_{2}$ inlet was charged with $200.0 \mathrm{~g}$ of rosin ( $0.66 \mathrm{~mol}$ rosin was considered a pure substance) and $38.4 \mathrm{~g}$ of FA $(0.33 \mathrm{~mol})$, purged with a $\mathrm{N}_{2}$ stream. The system was heated to $190{ }^{\circ} \mathrm{C}$ and maintained at this temperature for $1 \mathrm{~h}$, after which another $38.4 \mathrm{~g}$ of FA $(0.33 \mathrm{~mol})$ was added. The reaction was kept at $190{ }^{\circ} \mathrm{C}$ for $6 \mathrm{~h}$, and the resulting crude product was received. Then the crude products were removed from the flask, purified using the 
potassium salting-out method, and recrystallized from acetic acid. The products were collected and dried to obtain white crystals (yield: $83 \%$ ).

\subsection{Synthesis of Epoxy Resins (FPAE)}

FPAE was synthesized according to a previous work [29]. Briefly, a $250 \mathrm{~mL}$ fourneck round-bottomed flask, equipped with a reflux condenser, a mechanical stirrer, a thermometer, and a $\mathrm{N}_{2}$ inlet, was charged with FPA ( $\left.30 \mathrm{~g}, 0.073 \mathrm{~mol}\right)$, EC (122 g, $\left.1.32 \mathrm{~mol}\right)$, and $0.15 \mathrm{~g}$ of triethylamine $(0.1 \mathrm{wt} \%$ on the basis of the total weight of FPA and EC). The acidity of the system was monitored by titration with $\mathrm{KOH}$ ethanol solution. The temperature of the system was maintained at $110{ }^{\circ} \mathrm{C}$ until the acid number was less than $0.5 \mathrm{mg} \mathrm{KOH} / \mathrm{g}$. A total of $10 \mathrm{~g}$ of solid $\mathrm{KOH}(0.18 \mathrm{~mol})$ was added to the reaction after the temperature was cooled to $60^{\circ} \mathrm{C}$, and maintained at $65^{\circ} \mathrm{C}$ for $1 \mathrm{~h}$. Another $6 \mathrm{~g}(0.11 \mathrm{~mol})$ of solid $\mathrm{KOH}$ was then introduced into the system. The reaction was complete after the system was maintained at $65^{\circ} \mathrm{C}$ for $3 \mathrm{~h}$. Purification of the crude product was carried out via filtering to remove inorganic substances such as $\mathrm{KCl}$ and $\mathrm{KOH}$. The filtrate was washed with water several times until $\mathrm{pH}=7$ was reached, after which the water phase was removed. Purification was continued by heating at $80^{\circ} \mathrm{C}$ for $3 \mathrm{~h}$ to remove $\mathrm{EC}$ and $\mathrm{H}_{2} \mathrm{O}$ in a vacuum oven and obtain a yellow, transparent block product (yield: $78.5 \%$; theoretical epoxy value: $0.51 \mathrm{~mol} / 100 \mathrm{~g}$; found: $0.46 \mathrm{~mol} / 100 \mathrm{~g}$ ).

\subsection{Synthesis of C-FPAE Cross-Linking Network}

A typical reaction of BDB synthesized as reported [30] and FPAE is showed in Figure 1 to obtain C-FPAE networks. FPAE ( $3.00 \mathrm{~g}, 5.20 \mathrm{nmol})$ in a three-necked flask was dissolved in THF. A catalysis amount of 4-dimethylaminopyridine and BDB $(0.32 \mathrm{~g}, 1.04 \mathrm{nmol})$, which was synthesized as reported [31], were added under accelerating stirring until they dissolved. The mixture was quickly transferred to a release paper mold for $8 \mathrm{~h}$ at $120^{\circ} \mathrm{C}$ to get cured FPAE (20\% C-FPAE). BDB contents were 4.0, 8.0, 12.0, 16.0, 20.0, 50.0, and $100.0 \mathrm{~mol} \%$ relative to FPAE, and the abbreviation of $\mathrm{x} \%$ C-FPAE refers to cured FPAE with $\mathrm{x} \mathrm{mol} \%$ of BDB. However, the obtained 50\%C-FPAE and 100\%C-FPAE samples contained many bubbles, and even they were sequentially heated $\left(50^{\circ} \mathrm{C}, 2 \mathrm{~h} \rightarrow 80^{\circ} \mathrm{C}, 2 \mathrm{~h} \rightarrow 100^{\circ} \mathrm{C}\right.$, $2 \mathrm{~h} \rightarrow 120^{\circ} \mathrm{C} 2 \mathrm{~h}$ ) for curing, maybe due to the faster reaction at a high BDB content. Therefore, the properties of 50\%C-FPAE and 100\%C-FPAE could not be investigated.

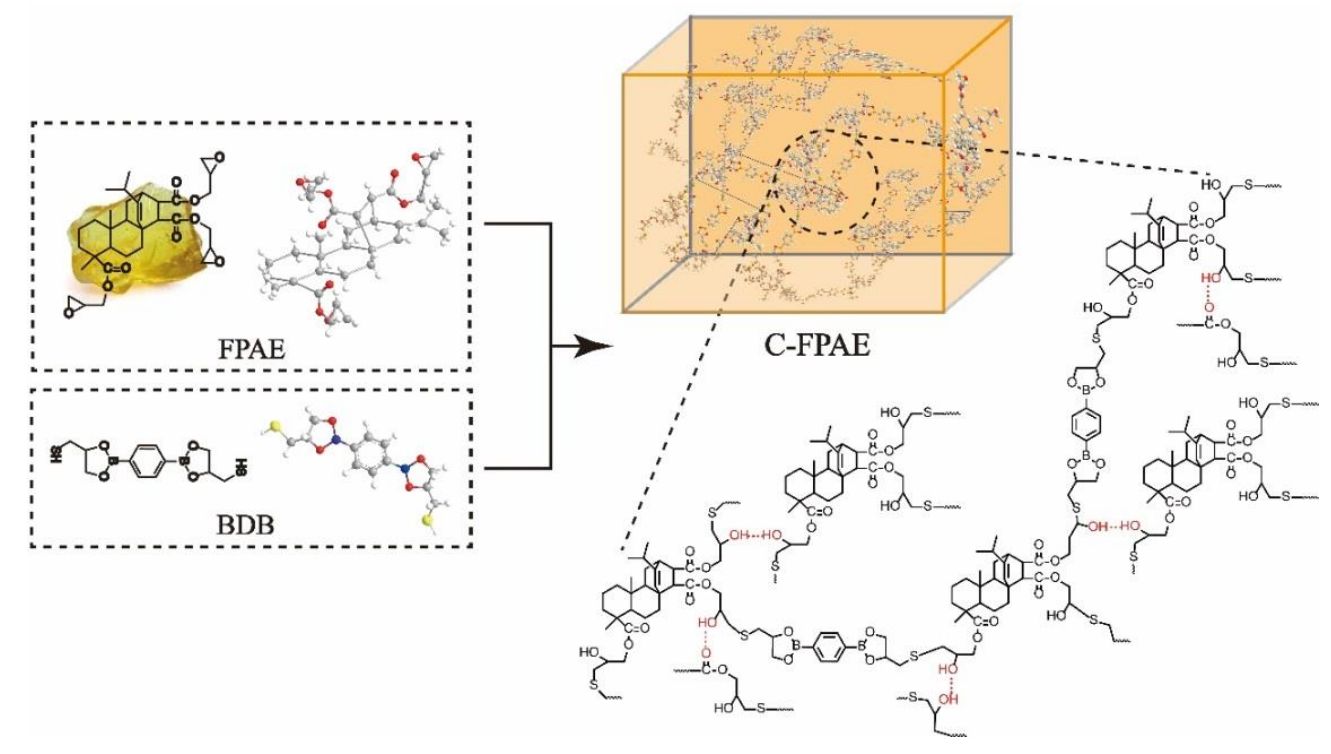

Figure 1. Synthesis of a C-FPAE cross-linking network. 


\subsection{Self-Healing, Welding, Shape-Memory, and Reprocessing}

Self-healing experiments were recorded using a polarizing optical microscope (POM) equipped with a heating stage and a UCMOS05100KPA (P/N: TP605100A) microscope camera, Hangzhou, China. The film sample (20\% C-FPAE) was cut using a razor to obtain cracks of comparable size. The cracked films were heated in an oven at $170{ }^{\circ} \mathrm{C}$ for $30 \mathrm{~min}$, and thereafter, the cracks were observed using a POM.

Welding was performed with two rectangular samples of $20 \%$ C-FPAE $(25 \mathrm{~mm} \times$ $5 \mathrm{~mm}$ ). They were held together with a superimposed length of $10 \mathrm{~mm}$ for holding times from $1 \sim 12 \mathrm{~h}$ at controlled temperatures $\left(130,140,150,160^{\circ} \mathrm{C}\right)$. Good contact was ensured after the heating treatment, and welding efficiency was evaluated by conducting tensile tests at room temperature with a cross-head speed of $5 \mathrm{~mm} / \mathrm{min}$ on the assembly and comparing the forces at break.

A strip sample (20\% C-FPAE) was checked to study the shape memory capability. The strip sample was put into an oven at $130^{\circ} \mathrm{C}$, bent into different shapes using an external force, and finally cooled down to room temperature. Digital photos of the strip sample before and after reshaping were recorded.

The reprocessing sample ( $20 \%$ C-FPAE) was crushed and ground into a powder using a $0.25 \mathrm{~mm}$ aperture screen ring to obtain a powder with a particle size of $0.25 \mathrm{~mm}$ or less. A hydraulic plate vulcanizer (ZS-406B-30-300, Dongguan Zhuosheng Machinery Equipment Co., Ltd.Dongguan, China) was used as reprocessing equipment, and the obtained sample powder was added into the mold for reprocessing under $10 \mathrm{MPa}$ pressure. Reprocessing was performed at $200{ }^{\circ} \mathrm{C}$ for $60 \mathrm{~min}$, and the process was repeated for three cycles.

\subsection{Degradation}

Chemical degradation of the 20\% C-FPAE samples was performed by immersing the powder samples $(0.5 \mathrm{~g})$ into a mixed solution of THF- $\mathrm{H}_{2} \mathrm{O}_{2}-\mathrm{HCl}$ with different $\mathrm{pH}(0.0,0.2$, $1.5,3.7,4.4,6.5)$ at $30^{\circ} \mathrm{C}$ for $48 \mathrm{~h}$ with stirring. The insoluble residuals were collected and vacuum-dried, and the degradation weight percentages were calculated. The soluble part was characterized by Fourier transform infrared spectroscopy (FTIR) and real-time Fourier transform infrared spectroscopy (real-time FTIR).

\subsection{Characterization}

FTIR spectra were collected using a Nicolet 205 FTIR spectrometer (Madison, USA) from 600 to $4000 \mathrm{~cm}^{-1}$ by the $\mathrm{KBr}$ tablet method. The thermal decomposition behavior of the FPAE and C-FPAE series was examined by means of thermogravimetry analysis (TGA) with a heating rate of $10 \mathrm{~K} / \mathrm{min}$ in a nitrogen atmosphere from 35 to $800^{\circ} \mathrm{C}$ on a TA Q500 (Milford, USA). Differential scanning calorimetry (DSC 204, NETZSCH, Germany) was performed at a heating rate of $5{ }^{\circ} \mathrm{C} / \mathrm{min}$ from 25 to $300{ }^{\circ} \mathrm{C}$ in a nitrogen atmosphere. The glass transition temperature, $T_{g}$, was obtained from the inflection point of the step of the curve by the thermomechanical method in the second cycle (heating to $200{ }^{\circ} \mathrm{C}$ ). Dynamic mechanical analysis (DMA) and stress relaxation tests were carried out using a TA Q800 (Milford, USA) instrument. The C-FPAE samples ( $5 \mathrm{~mm} \times 25 \mathrm{~mm} \times 1 \mathrm{~mm}$ ) were tested from 25 to $180{ }^{\circ} \mathrm{C}$ (heating rate $=3{ }^{\circ} \mathrm{C} \mathrm{min}{ }^{-1}$ ) with a frequency of $1 \mathrm{~Hz}$. Stress relaxation experiments were conducted by monitoring the stress decay at a constant strain of $1 \%$ after equilibrating at required temperatures for $20 \mathrm{~min}$. The mechanical performance test used the UTM4503SLXY universal tensile testing machine of Shenzhen Sansi Aspect Technology Co., Ltd. (Shenzhen, China), with a $5 \mathrm{~mm} / \mathrm{min}$ tensile rate. Young's modulus, elongation at break, and tensile strength were obtained by the mechanical performance test. The length of the original sample for mechanical testing was $40 \mathrm{~mm}$, and the length of the fractured sample was in the range of $40.5 \sim 42.4 \mathrm{~mm}$. The density of the polymer was measured by a TWS series touchscreen electronic densitometer (TWS-300S, Mzkeyi Co., Ltd., Shenzhen, China) for calculation of cross-linking density. Real-time FTIR spectra were collected using a ReactIR 15 (METTLER TOLEDO, Zurich, Switzerland) spectrometer from 
500 to $4000 \mathrm{~cm}^{-1}$ by a diamond probe. The shape memory performance of $20 \%$ C-FPAE was also examined by DMA. The sample with a rectangular shape $(35 \mathrm{~mm} \times 5 \mathrm{~mm} \times$ $1 \mathrm{~mm}$ ) was allowed to undergo two cycles at a temperature of $120^{\circ} \mathrm{C}$ and a rate of $3{ }^{\circ} \mathrm{C}$ $\min ^{-1}$, and a constant stress of $0.05 \mathrm{~N}$ was used to induce shape changing.

The sol fraction and swelling ratio were determined by an equilibrium swelling experiment based on the Flory-Rehner equation, as showin in Equations (1) and (2). It was conducted by immersing vulcanizate in toluene, THF, or acetone refluxing for $24 \mathrm{~h}$, and then solvent was wiped with filter paper. The samples were weighed immediately and dried in a vacuum oven at $60{ }^{\circ} \mathrm{C}$ until the weight was constant. Three specimens were measured for each sample. Assuming that the initial mass was $m_{0}$, the mass after swelling was $m_{1}$ and the mass after drying was $m_{2}$, and the swelling ratio and sol fraction were obtained:

$$
\begin{aligned}
& \text { Swelling ratio is defined as }=\frac{m_{1}-m_{2}}{m_{2}} \\
& \text { Sol fraction is determined as }=\frac{m_{0}-m_{2}}{m_{0}}
\end{aligned}
$$

The cross-linking density $\left(C_{d}\right)$ of the produced polymer was determined by the equilibrium swelling method with toluene as the solvent. The polymer was cut into five samples $(20 \mathrm{~mm} \times 10 \mathrm{~mm} \times 0.6 \mathrm{~mm})$, weighed, and immersed in a separate bottle containing $50 \mathrm{~mL}$ of toluene for 5 days. After equilibrium swelling was achieved, the sample was dried between the sheets and weighed again. The $C_{d}$ of the C-FPAE series was calculated by Flory-Rehner formula (Equation (3)) [32,33].

$$
\begin{gathered}
C_{d}=-\frac{\ln \left[\left(1-V_{r}\right)+V_{r}+\chi V_{r}^{2}\right]}{V_{s}\left(V_{r}^{1 / 3}-V_{r} / 2\right)} \\
V_{r}=\frac{m_{0} / \rho_{0}}{m_{0} / \rho_{0}+\left(m_{1}-m_{0}\right) / \rho_{c}} \\
\chi=0.487+0.228 V_{r}
\end{gathered}
$$

where $m_{0}$ is the initial mass of the sample, $m_{1}$ is the mass of the sample after swelling equilibrium, $\rho_{c}$ is the density of toluene, $\rho_{0}$ is the density of the polymer, $V_{r}$ is the volume fraction of the polymer, the calculation formula is Equation (4), $\chi$ is the interaction parameter between solvent and polymer, the simplified calculation formula is Equation (5), and $V_{s}$ is the molar volume of the solvent.

\section{Results and Discussion}

\subsection{Covalent Cross-Linking of O-CFER Using BDB}

Boronic ester-containing C-FPAE networks were fabricated based on the chemical reaction between thiols of $\mathrm{BDB}$ and the epoxy groups of FPAE, with BDB as a curing agent. The fact could be explicitly confirmed by FTIR spectra in Figure 2a. In the spectrum of $\mathrm{BDB}$, the absorption at $2548 \mathrm{~cm}^{-1}$ was ascribed to the stretching vibrations of -SH [34-36]. In the case of FPAE, the absorption peaks at 1253 and $911 \mathrm{~cm}^{-1}$ were attributed to the bending vibrations of the epoxy group [31]. The peak at $1727 \mathrm{~cm}^{-1}$ was attributed to the stretching vibrations of $-\mathrm{C}=\mathrm{O}$. Additionally, taking the absorption at $1727 \mathrm{~cm}^{-1}$ as a reference, the ratio of the peak intensity between 1727 and $1253 \mathrm{~cm}^{-1}(I(1727 / 1253)=5.82$ in Table 1) increased in cured 20\% C-FPAE relative to FPAE $(\mathrm{I}(1727 / 1253)=23.81)$ due to the reacted epoxy group, and with the BDB contents increasing (as Figure $2 b$ ), the value (I $(1727 / 1253)$ increased from 6.50 to 23.81 , indicating the more reacted epoxy group in $20 \%$ C-FPAE. Compared with the spectra of BDB and 20\% C-FPAE samples, the absorption related to $-\mathrm{SH}$ in $20 \% \mathrm{C}$-FPAE completely disappeared after curing. Besides, the peaks at 1253 and $911 \mathrm{~cm}^{-1}$ present in the $20 \%$ C-FPAE spectrum indicated the existence of an unreacted epoxy group in the networks, while these two peaks obviously decreased in the 20\% C-FPAE spectrum in comparison with those of FPAE. The above observations 
indicate the occurrence of a chemical reaction between thiols and epoxy groups. Moreover, the covalently cross-linked molecular architecture of the prepared C-FPAE sample can be further confirmed by the fact that it is insoluble in any organic solvent.

Hydrogen bonds are weaker than conventional covalent bonds but stronger than van der Waals forces, and it is believed that hydrogen bonds are present in the C-FPAE series. FTIR measurements were performed to verify the hydrogen bonds in the C-FPAE series with different BDB contents. As shown in Figure 2c,d), the peaks around 1717 and $3520 \mathrm{~cm}^{-1}$ were assigned to carbonyl and hydroxyl, and the two characteristic peaks were red-shifted, widened, or strengthened due to the formation of hydrogen bonds [36,37]. The absorption peaks at 3280 and $3401 \mathrm{~cm}^{-1}$ in Figure 2c were attributed to the intramolecular hydrogen bond $\mathrm{O}-\mathrm{H} \cdots \mathrm{O}=\mathrm{C}$ and the intermolecular hydrogen bond $\mathrm{OH} \cdots \mathrm{O}$ or $\mathrm{OH} \cdots \mathrm{O}=\mathrm{C}$, respectively [37-40], and the absorption peak shifted to lower wavenumbers when the BDB content increased from $4 \%$ to $20 \%$, indicating more hydrogen bond formation at a higher BDB content.
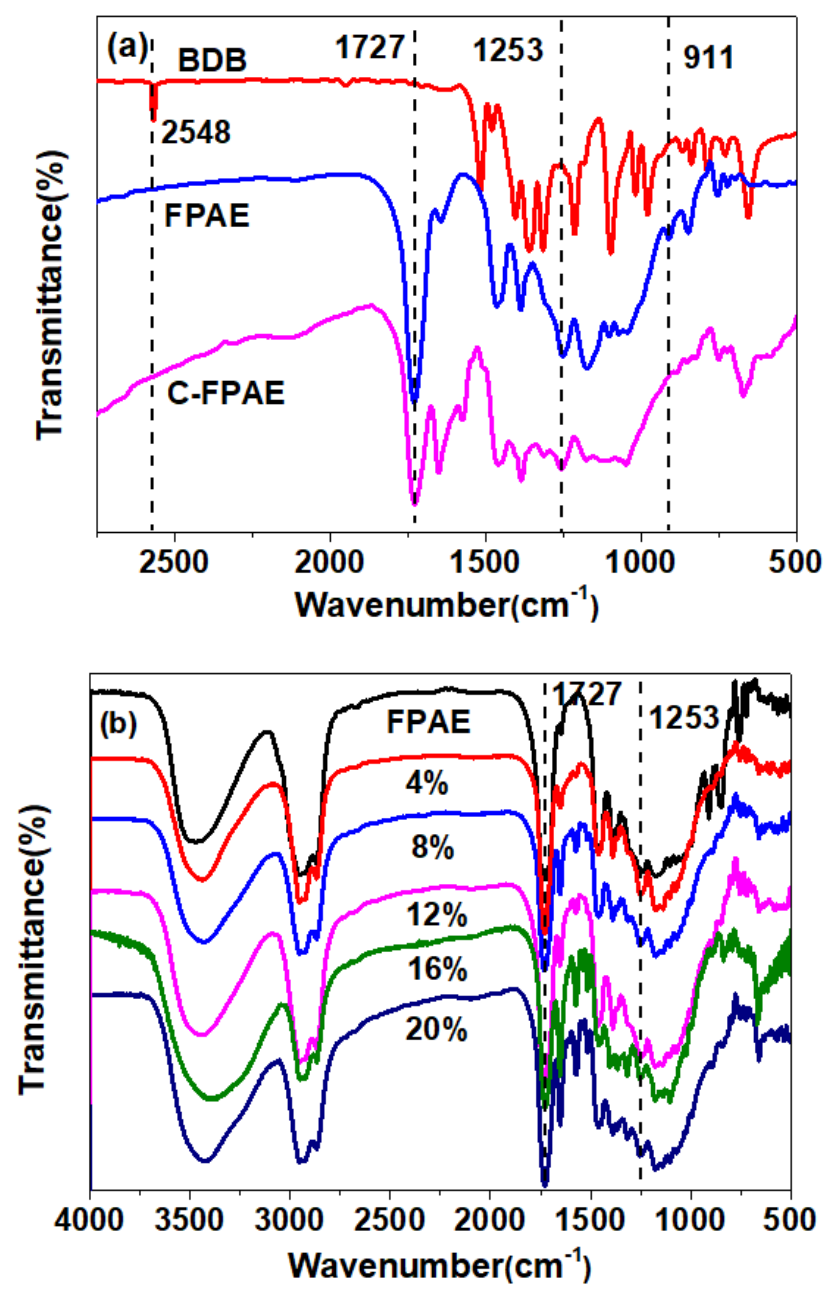

Figure 2. Cont. 

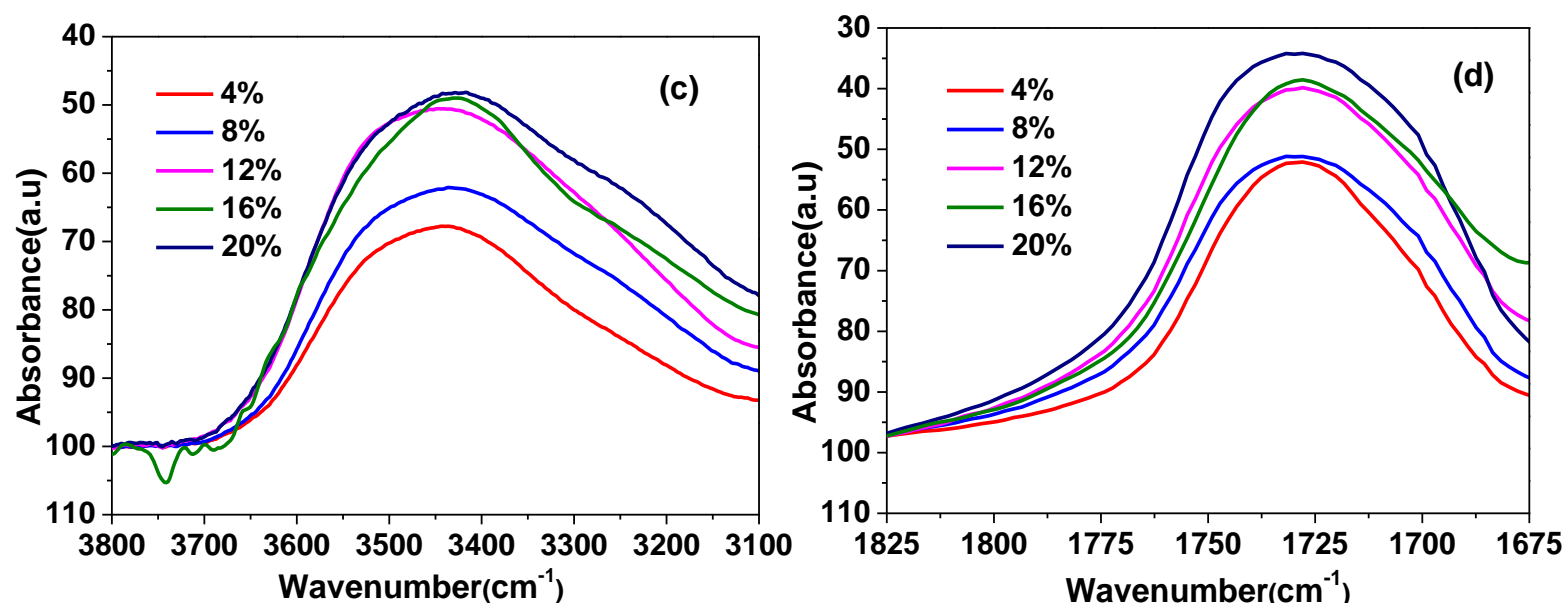

Figure 2. FTIR spectra of (a) BDB, FPAE, and 20\% C-FPAE and (b) C-FPAE series with different BDB contents. (c) Hydroxyl and (d) carbonyl.

Table 1. The ratio of peak intensity between 1727 and $1253 \mathrm{~cm}^{-1}$ of FPAE and C-FPAE with different BDB contents.

\begin{tabular}{cc}
\hline Sample & I (1727/1253) \\
\hline FPAE & 5.82 \\
4\% C-FPAE & 6.50 \\
8\% C-FPAE & 8.13 \\
12\% C-FPAE & 11.37 \\
16\% C-FPAE & 18.45 \\
20\% C-FPAE & 23.81 \\
\hline
\end{tabular}

Equilibrium swelling experiments showed that the cured C-FPAE series cannot be completely dissolved in toluene, THF, or acetone, and there was only a certain degree of swelling, which originated from the nature of a covalently cross-linked networks. The cross-linking density of the C-FPAE series consistently increased $\left(0.33 \sim 0.85 \mathrm{~mol} \cdot \mathrm{cm}^{-3}\right)$ with increase in the BDB content from $4 \%$ to $20 \%$ (Figure 3), revealing that a denser network is formed at a higher $\mathrm{BDB}$ content. Consequently, the sol fraction and swelling ratio monotonously decreased with the BDB load increasing [31,34].

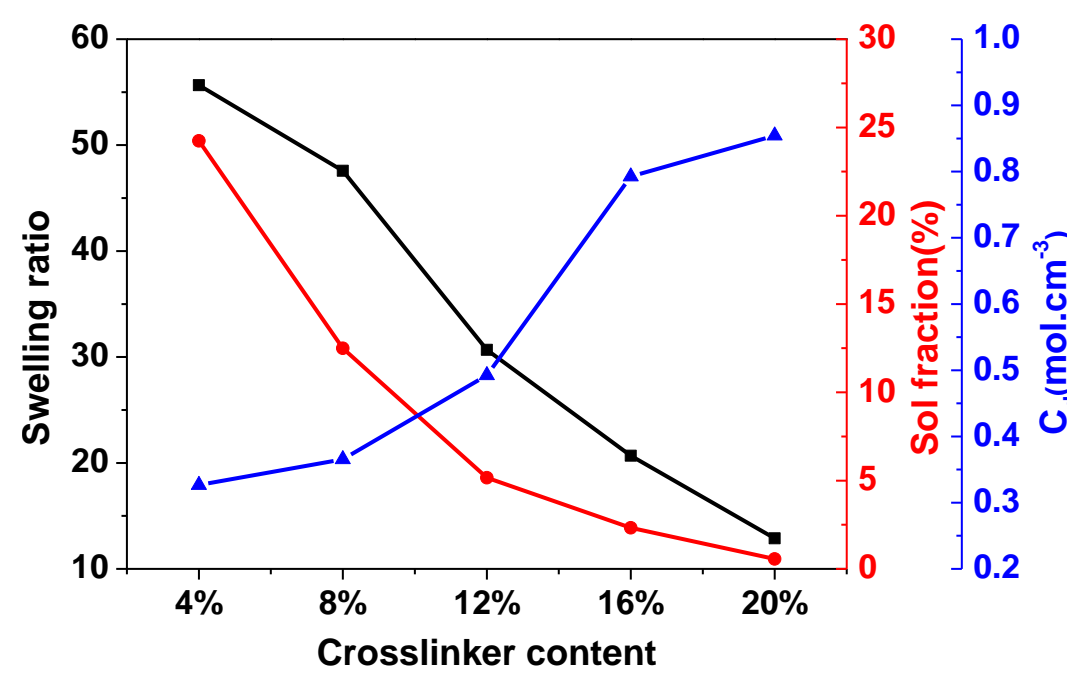

Figure 3. The cross-linking density, swelling ratio, and sol fraction of the C-FPAE series with different BDB contents. 


\subsection{Mechanical Properties, Thermal Performance, and Dynamic Property Analysis}

The representative stress-strain curves of the C-FPAE series with different BDB contents as well as pristine FPAE are shown in Figure 4a, and the mechanical properties are exhibited in Figure $4 \mathrm{~b}$. Pristine FPAE without cross-linking was stiff and relatively brittle, since the FPAE monomer includes epoxy and benzene groups. At a $2 \mathrm{~mm} / \mathrm{min}$ strain rate, Young's modulus was measured to be $1.7 \mathrm{MPa}$, with a tensile strength of $4.9 \mathrm{MPa}$ and a strain at breaking of $2.5 \%$. After curing by the BDB curing agent, the C-FPAE series was more ductile and tougher. Additionally, the mechanical properties could be facilely changed by varying the BDB content. Typically, increased BDB contents led to an enhancement in elongation at break and tensile strength as well as Young's modulus. For instance, in comparison with those of FPAE, the Young's modulus, elongation at break, and tensile strength of 20\% C-FPAE increased from 1.7 to $3.9 \mathrm{MPa}$, from $2.5 \%$ to $9.1 \%$, and from 4.9 to $39.5 \mathrm{MPa}$, respectively (Table 2). Increased BDB content brings out a more constrained network and restricted chain mobility due to increased cross-linking density. The mechanical properties of $20 \%$ C-FPAE were higher than those of epoxy vitrimers in the reported works (tensile strength was 10 vs. $4 \mathrm{MPa}$, elongation at break was $0.6 \%$ vs. $3.2 \%)[30,41]$. It is noted that the Young's modulus of $20 \%$ C-FPAE decreased with increasing BDB content. The origin of improved mechanical properties of the C-FPAE series should be the robust features of boronic ester bonds [31].
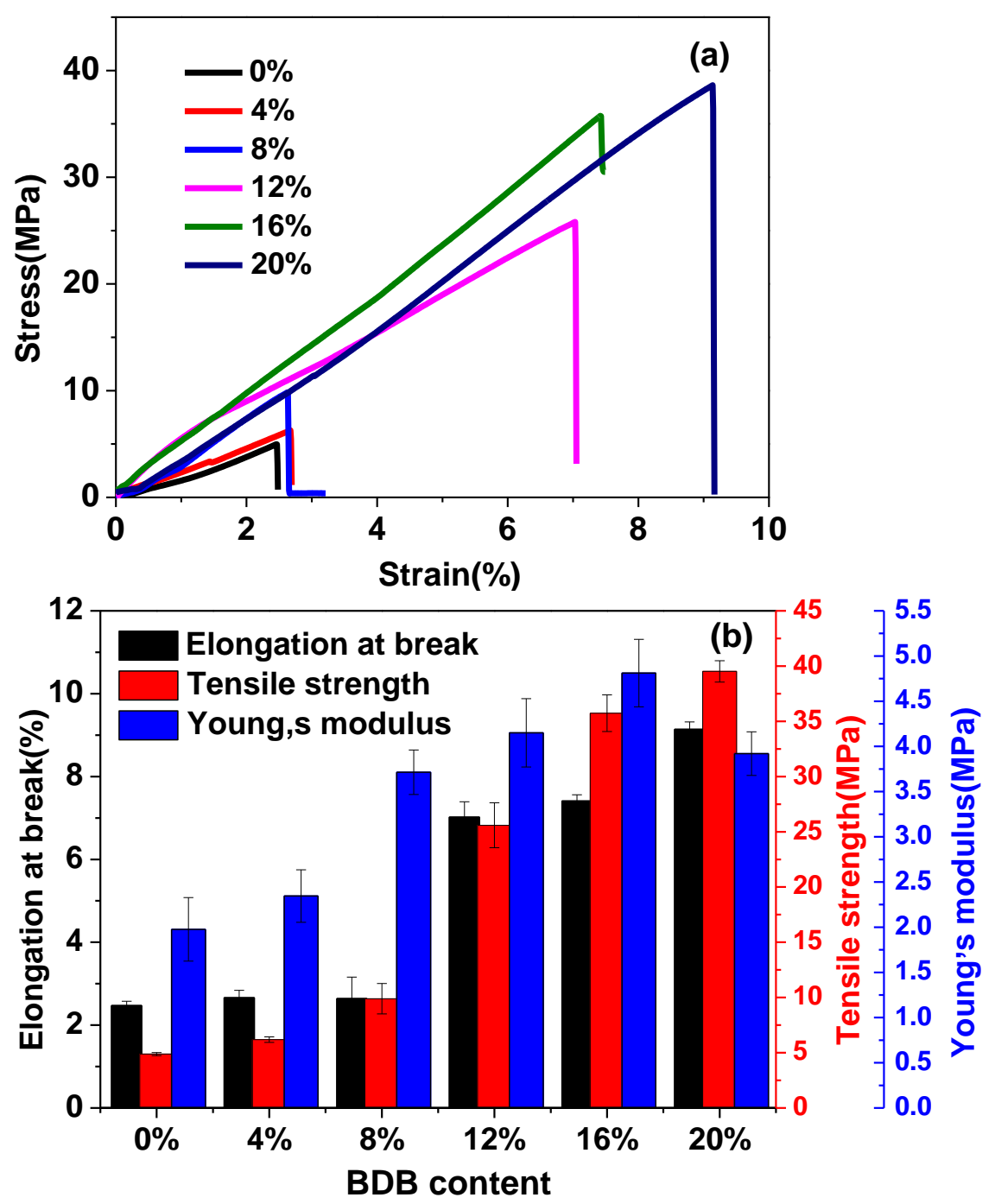

Figure 4. Mechanical properties of FPAE and C-FPAE series with different BDB contents: (a) stressstrain curve, (b) mechanical properties of the $\mathrm{x} \%$ C-FPAE series with different cross-linker contents. 
Table 2. Mechanical and thermal properties of FPAE and C-FPAE with different BDB contents.

\begin{tabular}{cccccc}
\hline Sample & $\begin{array}{c}\boldsymbol{T}_{\boldsymbol{g}} \\
\left({ }^{\circ} \mathbf{C}\right)\end{array}$ & $\begin{array}{c}\mathbf{E}^{\prime}\left(\boldsymbol{T}_{\boldsymbol{g}}+\mathbf{4 0}{ }^{\circ} \mathbf{C}\right) \\
\mathbf{( M p a )}\end{array}$ & $\begin{array}{c}\text { Elongation at Break } \\
\mathbf{( \% )}\end{array}$ & $\begin{array}{c}\text { Tensile Strength } \\
\mathbf{( M p a )}\end{array}$ & $\begin{array}{c}\text { Young's Modulus } \\
(\mathbf{M p a})\end{array}$ \\
\hline FPAE & 62 & $/$ & $2.5 \pm 0.1$ & $4.9 \pm 0.1$ & $1.7 \pm 0.4$ \\
$4 \%$ C-FPAE & 72 & 3.2 & $2.7 \pm 0.1$ & $6.2 \pm 0.2$ & $2.4 \pm 0.3$ \\
8\%C-FPAE & 82 & 4.1 & $2.7 \pm 0.5$ & $9.9 \pm 1.0$ & $3.7 \pm 0.2$ \\
12\%C-FPAE & 96 & 5.5 & $7.0 \pm 0.4$ & $3.6 \pm 0.1$ & $4.2 \pm 0.3$ \\
16\%C-FPAE & 106 & 7.8 & $9.1 \pm 0.2$ & $39.5 \pm 1.6$ & $4.8 \pm 0.4$ \\
20\% C-FPAE & 111 & 61.9 & & & $3.9 \pm 0.3$ \\
\hline
\end{tabular}

The thermal stability of the C-FPAE series was researched by TGA at a heating rate of $10{ }^{\circ} \mathrm{C} / \mathrm{min}$ under a nitrogen atmosphere, and the results are shown in Figure 5. Thermal stability factors, including initial decomposition temperature (the temperature of $5 \%$ weight loss, $\left.T_{5 d}\right)$ and the temperature of $50 \%$ weight loss $\left(T_{50 d}\right)$ were determined by TGA. The values of $T_{5 d}, T_{50 d}$, and residual weight at $500 / 800{ }^{\circ} \mathrm{C}$ for the C-FPAE series are summarized in Table 3. It was observed that $T_{5 d}$ and $T_{50 d}$ of the C-FPAE series increased with increasing BDB content. The $T_{5 d}$ of the C-FPAE series (BDB contents $4 \sim 20 \%$ ) increased from 234.3 to $340.7^{\circ} \mathrm{C}$; however, the $T_{5 d}$ of the FPAE monomer was only $214.5^{\circ} \mathrm{C}$. The residual weight at $500 / 800{ }^{\circ} \mathrm{C}$ was obviously enhanced by the introduction of the BDB curing agent due to the increased amount of sulfur and boron, and with the increasing BDB content, the thermal stability of C-FPAE prominently improved, and 20\% C-FPAE showed the highest thermal stability $\left(7.96 \%\right.$ at $500{ }^{\circ} \mathrm{C}$ and $6.44 \%$ at $\left.800{ }^{\circ} \mathrm{C}\right)$. The superior thermal stability of C-FPAE is attributed to the enhanced covalent cross-linker at higher contents of BDB, the improvement of the rosin framework, and the hydrogen bond in the networks $[42,43]$.
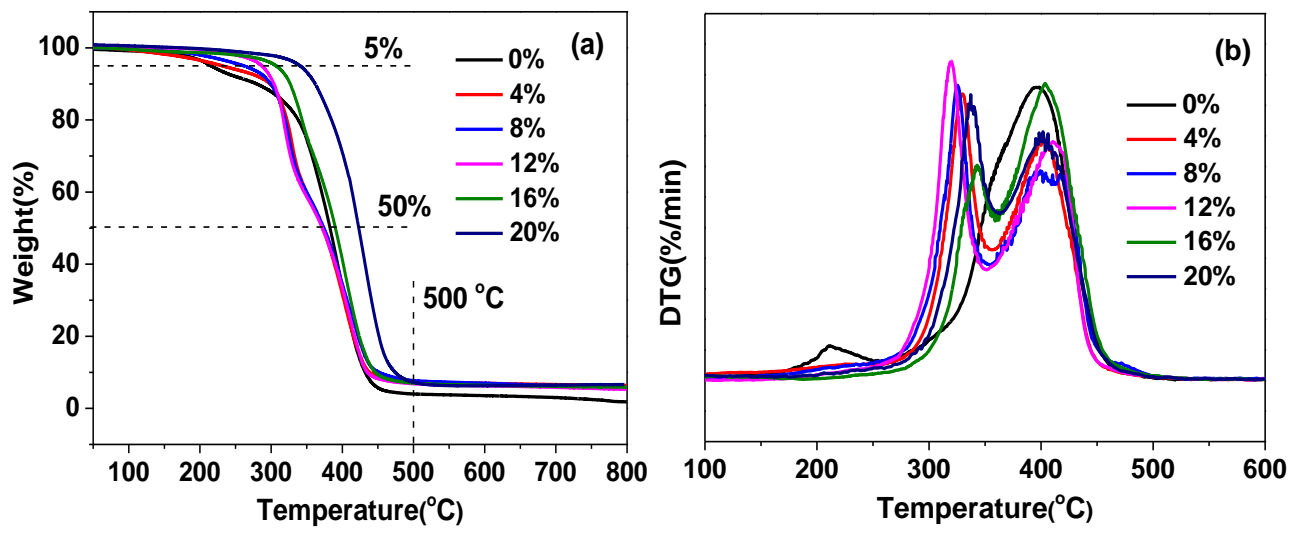

Figure 5. TGA (a) and DTG (b) curves of FPAE and C-FPAE series with different BDB contents.

Table 3. Thermal stability factors of FPAE and C-FPAE obtained from TGA and DTG curves.

\begin{tabular}{ccccc}
\hline Sample & $\boldsymbol{T}_{\mathbf{5} \boldsymbol{d}}\left({ }^{\circ} \mathbf{C}\right)$ & $\boldsymbol{T}_{\mathbf{5 0 d}}\left({ }^{\circ} \mathbf{C}\right)$ & $\begin{array}{r}\text { Residual Weight } \\
\text { at } \mathbf{5 0 0}^{\circ} \mathbf{C} \mathbf{( \% )}\end{array}$ & $\begin{array}{c}\text { Residual Weight } \\
\text { at } \mathbf{8 0 0}{ }^{\circ} \mathbf{C} \mathbf{( \% )}\end{array}$ \\
\hline FPAE & 214.5 & 381.9 & 3.98 & 1.87 \\
4\%C-FPAE & 234.3 & 371.5 & 6.26 & 4.61 \\
8\%C-FPAE & 259.5 & 372.3 & 6.72 & 5.07 \\
12\%C-FPAE & 287.4 & 375.6 & 7.17 & 5.41 \\
16\%C-FPAE & 307.3 & 390.4 & 7.63 & 5.98 \\
20\% C-FPAE & 340.7 & 423.9 & 7.96 & 6.44 \\
\hline
\end{tabular}

To adjust the welding and reprocessing performance of C-FPAE, $T_{g}$ is an important parameter. DSC curves are shown in Figure 6. In terms of the DSC curves in Figure 6, $T_{g}$ of the FPAE monomer was only $62{ }^{\circ} \mathrm{C}$. As the BDB content increased from $4 \%$ to $20 \%$, the $T_{g}$ of the C-FPAE series continuously increased from 72 to $111^{\circ} \mathrm{C}$, because with the BDB content 
increasing, more epoxy groups reacted and a higher cross-linking degree was achieved, giving a higher $T_{g}$ [44]. In addition, compared with other types of biobased thermosetting epoxy resins $\left(T_{g}\right.$ lower than $\left.80^{\circ} \mathrm{C}\right)$, the C-FPAE series with rosin as a matrix displayed a higher $T_{g}[45,46]$. With the aim of developing new epoxy resins that simultaneously show excellent welding and reprocessing capability, 20\% C-FPAE having the maximum $T_{5 d}, T_{50 d}$, and $T_{g}$ was selected for evaluating the mentioned capability $[3,47,48]$. Besides, in terms of the $T_{g}\left(125^{\circ} \mathrm{C}\right)$ of $20 \% \mathrm{C}-\mathrm{FPAE}$, the temperatures of welding and reprocessing were set higher than $125^{\circ} \mathrm{C}$, expecting rapid shaping recovery and facile reprocessing.

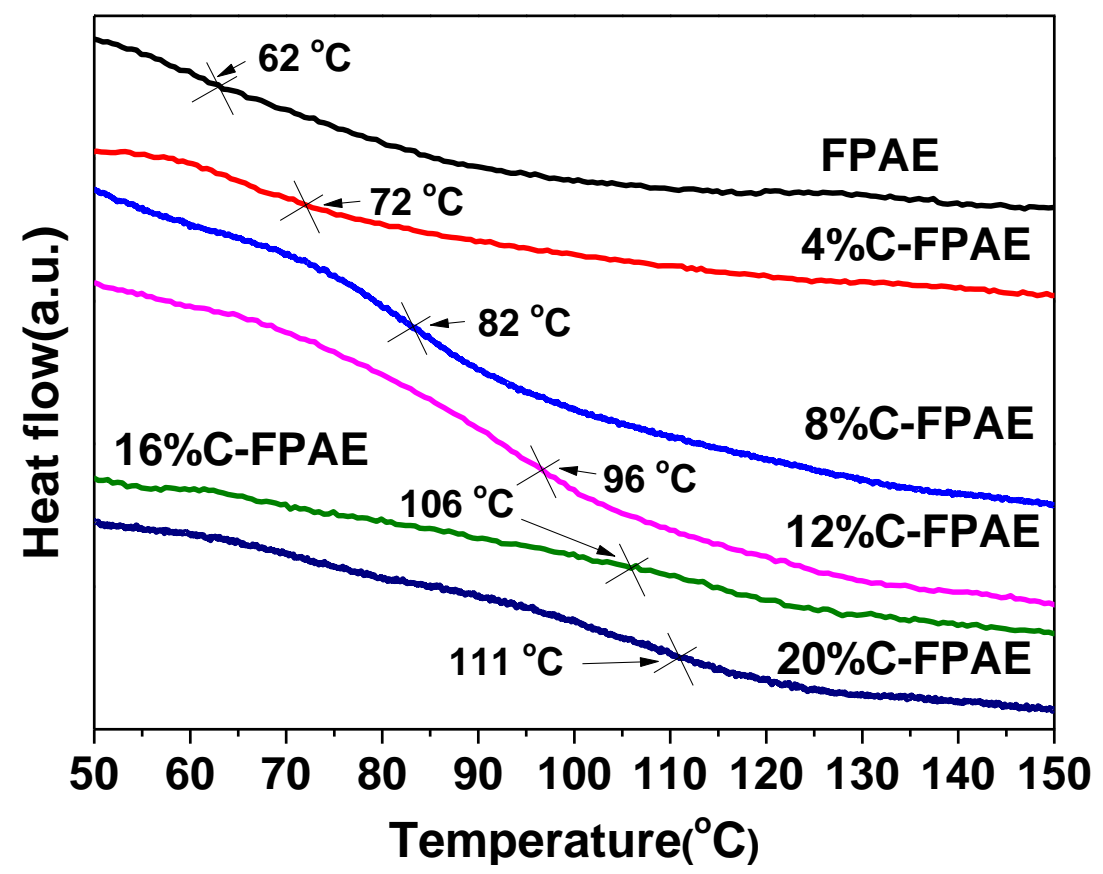

Figure 6. DSC curves of FPAE and C-FPAE series.

Stress relaxation experiments were conducted with DMA to evaluate the dynamic properties of the C-FPAE series. A deformation of $1 \%$ was used, and the decrease in stress was measured at different times but constant temperature $\left(80,100,110,120,130\right.$, or $\left.140{ }^{\circ} \mathrm{C}\right)$. Based on the Maxwell model for viscoelastic fluids, relaxation times were taken when the normalized stress decreased to 1/e of the initial stress. As shown in Figure 7a, the relaxation times decreased from $160 \mathrm{~s}$ at $100{ }^{\circ} \mathrm{C}$ to $24 \mathrm{~s}$ at $140{ }^{\circ} \mathrm{C}$, and complete stress relaxation was accomplished above $120^{\circ} \mathrm{C}$. The temperature dependence of the relaxation time followed Arrhenius' law (Figure 7b), which is given by Equation (6), and an activation energy $E_{a}$ of $49 \mathrm{~kJ} \cdot \mathrm{mol}^{-1}$ was obtained from the slope [3]. This result that the viscoelastic behavior of $20 \%$ C-FPAE follows Arrhenius' law is the first to reveal rosin-based vitrimer materials.

$$
\ln \tau=\ln \tau_{0}+\frac{E_{a}}{R T}
$$

The topology freezing transition temperature $\left(T_{v}\right)$ is a key parameter for vitrimers [6,49], and it corresponds to the transition from a solid to a viscous fluid. $T_{v}$ is conventionally defined as the temperature where the viscosity reaches $10^{12} \mathrm{~Pa} \cdot \mathrm{s}$, and it was determined to be $-31^{\circ} \mathrm{C}$ in our system by extrapolating from the Arrhenius fitted line to a relaxation time of $4.8 \times 10^{5} \mathrm{~s}$. The borate exchange reaction has lower $E_{a}$ and $T_{v}$, and the low $T_{v}$ should give a fast exchange reaction, consistent with its fast relaxation time at high temperature [10,50,51]. However, 20\% C-FPAE displayed only slight stress relaxation at room temperature, since its network was frozen by the lack of segmental motions associated with a higher $T_{g}$. 
The effects of the BDB content on the $\alpha$-relaxation and storage modulus of the C-FPAE series were studied. The plots of the storage modulus and $\tan \delta$ for the C-FPAE series with different BDB contents are shown in Figures S1 and S2 (in Supplementary Materials). The typical $\tan \delta$ plot of C-FPAE showed two loss peaks at round 61 and $125^{\circ} \mathrm{C}$ (Figure S2). The two loss peaks are typical for polymers with different components [52-54]. The weak loss peak at $61{ }^{\circ} \mathrm{C}$ came from the incompletely cross-linked FPAE ingredients in the C-FPAE series. As the C-FPAE series warmed up, the main loss peak was found at $125^{\circ} \mathrm{C}$, as the second component of the macromolecular C-FPAE chain lost its mechanical integrity. The peaks around $125^{\circ} \mathrm{C}$ of the tan $\delta$ curve became dominant with the increase in BDB contents, due to the sufficiently reacted epoxy group in C-FPAE. The $T_{g}$ (round $125^{\circ} \mathrm{C}$ ) was higher than that obtained by DSC due to different characterization methods. Additionally, the CFPAE with a higher BDB content displayed a higher rubber platform $\left(E^{\prime}\right)$, and $20 \%$ C-FPAE showed the highest $E^{\prime}$ (61.9 MPa; Table 2), maybe because network integrity became much better at a BDB content of $20 \%$, consisting of a tan $\delta$ plot of $20 \%$ C-FPAE with one dominate peak at $125{ }^{\circ} \mathrm{C}$. This phenomenon should be related to the cross-linking density of the C-FPAE series, and the C-FPAE with a higher BDB content provides a more well-developed network structure, which restricts the chain mobility and thus enhances the elastic response of the network. Therefore, the enhanced storage modulus and the reduced peak height of the $\tan \delta$ plot originate from the increasing BDB content of the C-FPAE series [52].
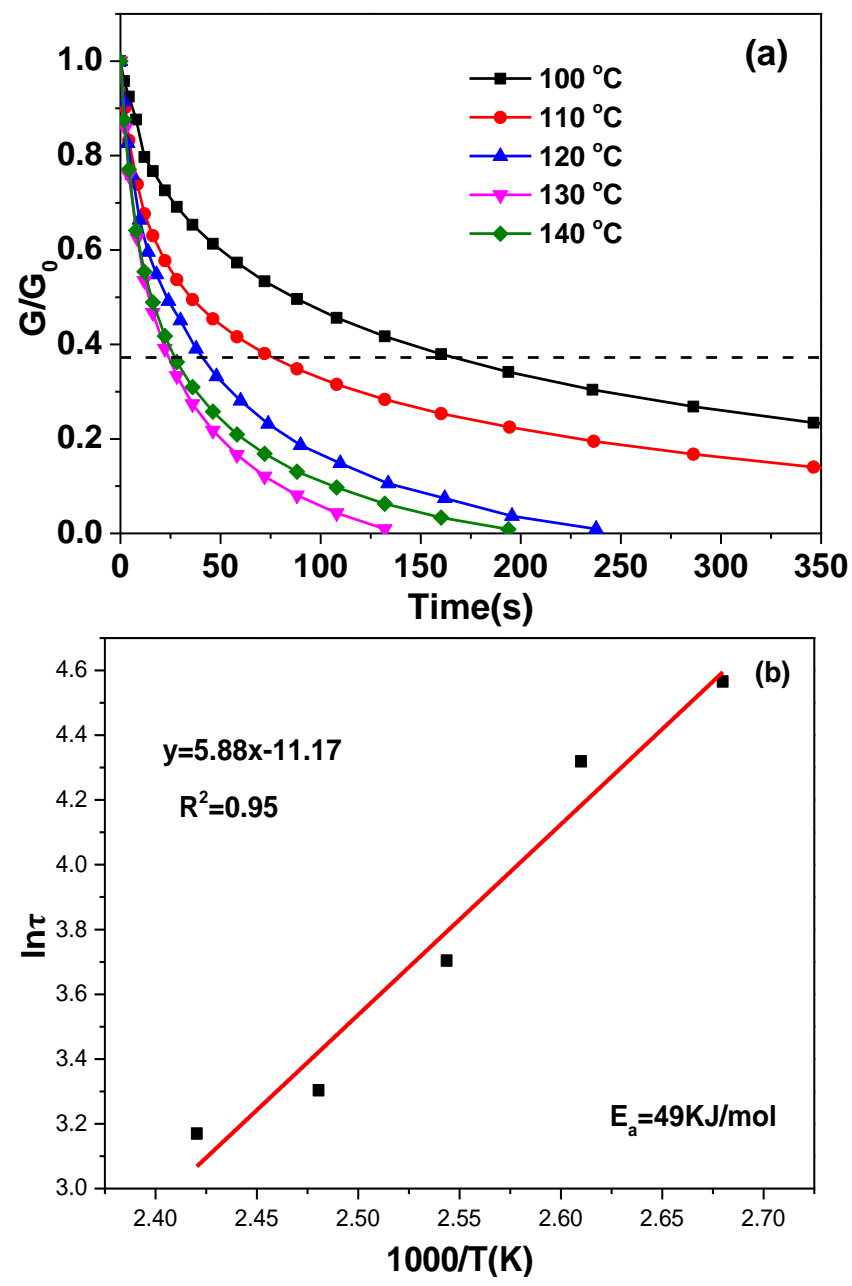

Figure 7. (a) Stress relaxation study of $20 \%$ C-FPAE. (b) Arrhenius plot with linear fit for 20\% C-FPAE.

\subsection{Self-Healing, Welding, and Shape Memory}

Network rearrangement and bond reshuffling can take place, and covalent bonding can be re-established across the interfaces of fractured surfaces, because of the transesterifi- 
cation reaction of boronic ester linkages, as described in Figure 8d. As a result, 20\% C-FPEA should acquire self-healing ability by boronic ester bond exchange-induced network rearrangement. The $20 \%$ C-FPEA sheet sample with a thickness of $0.7 \mathrm{~mm}$ was cut using a razor to a width of $117 \mu \mathrm{m}$ to examine its self-healing capability. The cut sample had healing treatment at $170{ }^{\circ} \mathrm{C}$ for $30 \mathrm{~min}$ in the oven. As shown in Figure 8a, 20\% C-FPEA exhibited good self-healing capability and only $30 \mathrm{~min}$ healing treatment led to more than $80 \%$ recovery.
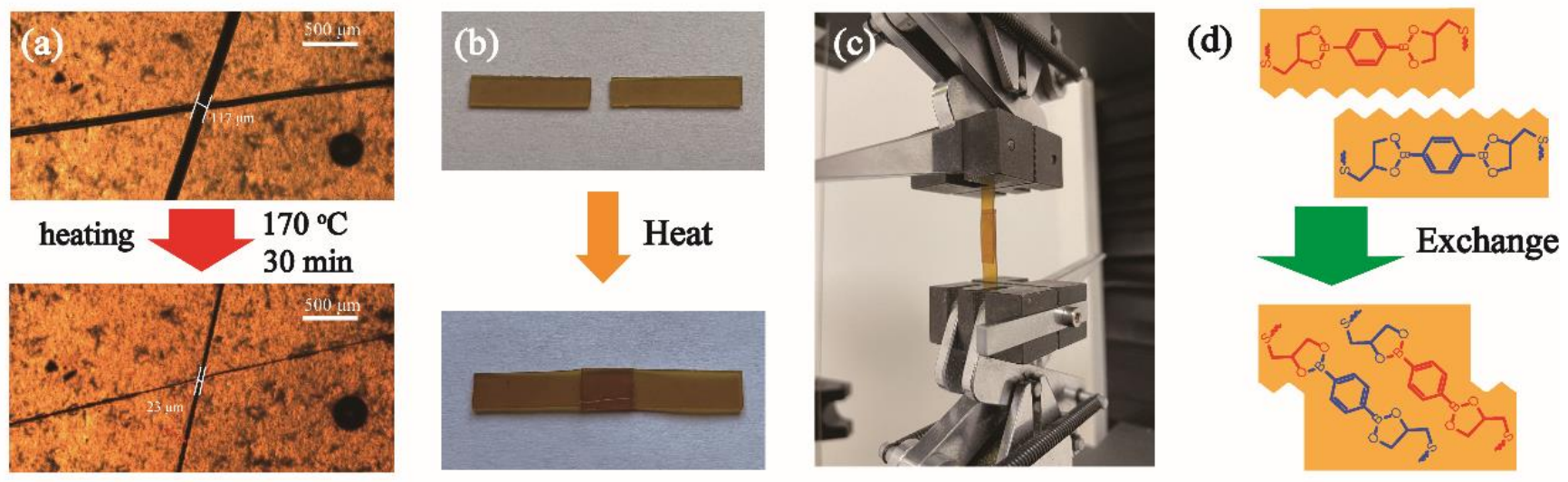

Figure 8. (a) Optical microscope images of self-healing performance for 20\%C-FPEA. (b) Optical microscope images of welding performance. (c) Photograph of a sample during the lap-shear test. (d) Schematic representation of the transesterification reaction of boronic ester linkages.

To investigate the welding properties of $20 \%$ C-FPEA networks, the lap-shear test was used (Figure 8c), although the test is intrinsically difficult to pass for polymeric assemblies, as a fracture is easily initiated at the interface. Two rectangular samples of $20 \%$ C-FPEA $(20.0 \mathrm{~mm} \times 5.0 \mathrm{~mm} \times 0.7 \mathrm{~mm})$ were superimposed on an $8.0 \mathrm{~mm}$ length (Figure $8 \mathrm{~b}$ ) and held together under pressure for welding times ranging from 1 to $12 \mathrm{~h}$ at a controlled temperature $\left(130,140,150,160^{\circ} \mathrm{C}\right)$. Remarkable contact was ensured by applying compression during the treatment. The mechanical properties of the welded samples were then evaluated by carrying out tensile tests at room temperature with a cross-head speed of $2 \mathrm{~mm} / \mathrm{min}$. We consider that the network could be frozen as the temperature decreased below $T_{g}$, so we chose a temperature higher than $T_{g}$ as the reprocessing temperature. Stress-strain curves of assemblies of 20\% C-FPEA with different heating times $(1,4,8,12 \mathrm{~h})$ at $160{ }^{\circ} \mathrm{C}$ are shown in Figure 9a. With extended heating times, the mechanical properties of the assemblies gradually improved, and finally the highest mechanical properties were achieved by $12 \mathrm{~h}$ heating with elongation at break of $9.2 \%$, tensile strength of $39.8 \mathrm{MPa}$, and Young's modulus of 4.3 MPa. As expected, the mechanical properties of the welded samples increased by elevating the treating temperature (Figure 9d). When the treating temperature was elevated from $130^{\circ} \mathrm{C}$ to $160^{\circ} \mathrm{C}$ for $12 \mathrm{~h}$, continuously improved mechanical properties were obtained. The mechanical properties sharply increased at $160^{\circ} \mathrm{C}$, and the stress-stain curve of $20 \%$ C-FPEA after welding at $160^{\circ} \mathrm{C}$ almost overlapped with that of the pristine sample (Figure 9c). The present results demonstrate that 20\% C-FPEA containing a dynamic cross-linking network possesses attractive thermal healing and welding capabilities. 

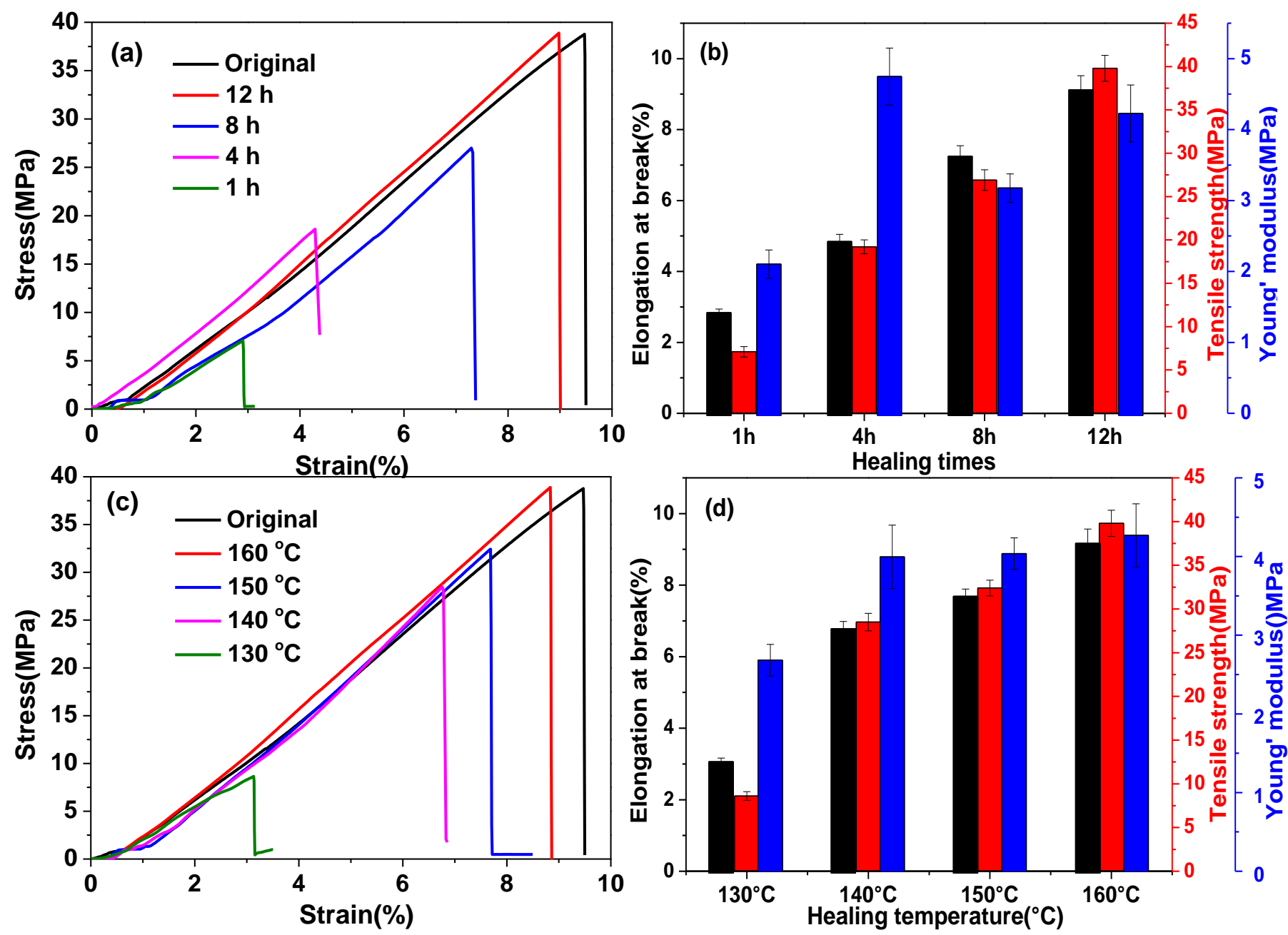

Figure 9. (a) Tensile curves of $20 \%$ C-FPEA welding at $160{ }^{\circ} \mathrm{C}$ for various times. (b) Mechanical properties of $20 \%$ CFPEA welded at $160{ }^{\circ} \mathrm{C}$ for various times. (c) Tensile curves of $20 \%$ C-FPEA welding at $12 \mathrm{~h}$ for various temperatures.

(d) Mechanical properties of $20 \%$ C-FPEA welded at $12 \mathrm{~h}$ for various temperatures.

It is inherently difficult to reshape a typical cured polymer due to a permanent crosslinking network. Herein, the boronic ester undergoes an associative transesterification reaction in the network, which provides network rearrangement and contributes to a gradual Arrhenius-like viscosity dependence, giving the network the ability to be reshaped in a solid state. As a proof-of-concept, a strip-shaped sample of 20\% C-FPAE was first heated to $130{ }^{\circ} \mathrm{C}$ in the oven and turned into an oblique shape that could be fixed when the temperature decreased to room temperature. When the temperature increased to $130{ }^{\circ} \mathrm{C}$ again, the shape of $\mathrm{S}$ reverted to its original flat state within $2 \mathrm{~min}$ and then recovered by following the same heating-cooling procedure. As a representative, Figure 10 shows digital photos of $20 \%$ C-FPAE before and after shaping. The shape change is reversible, and the process is repeatable, since the thermally induced dynamic exchange reaction is attributed to the reorganization of the cross-linked covalent network $[55,56]$. Moreover, shape memory cycles [57] were conducted by DMA (Figure S3 in Supplementary Materials). At the initial shape memory cycle, 20\% C-FPAE displayed a shape fixation ratio $\left(R_{f}\right)$ of $86 \%$ and a shape recovery ratio $\left(R_{r}\right)$ of $59 \%$. 


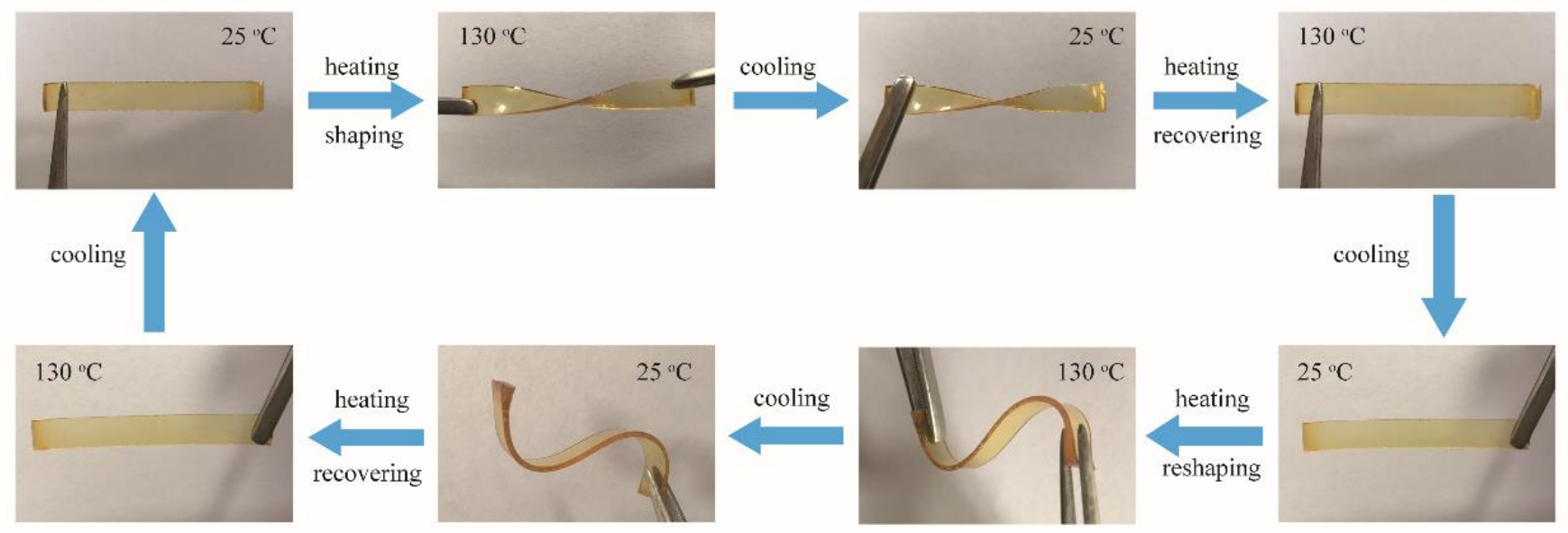

Figure 10. Optical microscope images of shape-memory performance of the $20 \%$ C-FPAE sample.

\subsection{Reprocessing}

In addition to the highly improved mechanical properties, shape memory capabilities and self-healing capabilities, the rosin vitrimer also demonstrates another smart property, reprocessability. The polymer networks of rosin vitrimers are only exchanged without consumptions during the recycling operation; therefore, several cycles might be achieved. To verify the reprocessability, the $20 \%$ C-FPAE sample was pulverized into a powder by using the same grade of sandpaper and then hot-pressed at $200{ }^{\circ} \mathrm{C}$ for $60 \mathrm{~min}$, and homogeneous samples were obtained (Figure 11a). To quantify and qualify the reprocessability, the mechanical properties and FTIR measurement of the original and multiple recycled samples were examined. The intensity and wavelength of characteristic peaks at 1727 and $1253 \mathrm{~cm}^{-1}$ responding to $-\mathrm{C}=\mathrm{O}$ and epoxy groups, respectively, in the FTIR spectra (Figure 11b) before and after several reprocessing cycles did not change, indicating similar chemical structures of the reprocessed and original samples and a high thermal stability of the C-FPAE series. Besides, recovery ratios of the mechanical properties of the recycled samples are shown in Figure 11d. It was observed that most mechanical properties were restored after reprocessing. For example, the recovery ratios of tensile strength, Young's modulus, and elongation at break for the sample were $92 \%, 106 \%$, and $95 \%$, respectively. The stress-strain curves are shown in Figure 11c, and it is remarkable to note that even after reprocessing three times, the third-generation sample could lead to a tensile strength of $81 \%$ and a Young's modulus of $90 \%$. More strikingly, the samples could be repeatedly recycled because of the robust characteristic of the dynamic boronic ester bonds in the rosin vitrimer. Figure $11 \mathrm{~b}$ shows the evolution of the ultimate stretch as a function of the number of time recycling was done. The properties of the recycled sample decay over the number of times recycling is done, while it stays in a reasonably good range, confirming that the boronic ester transesterification reaction plays a critical role in the reprocessing of rosin vitrimers [10]. 


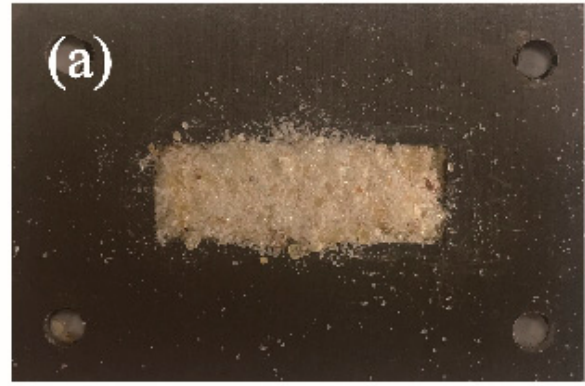

Pulverization

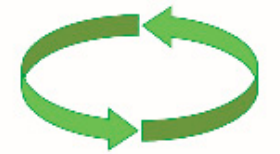

Hot press
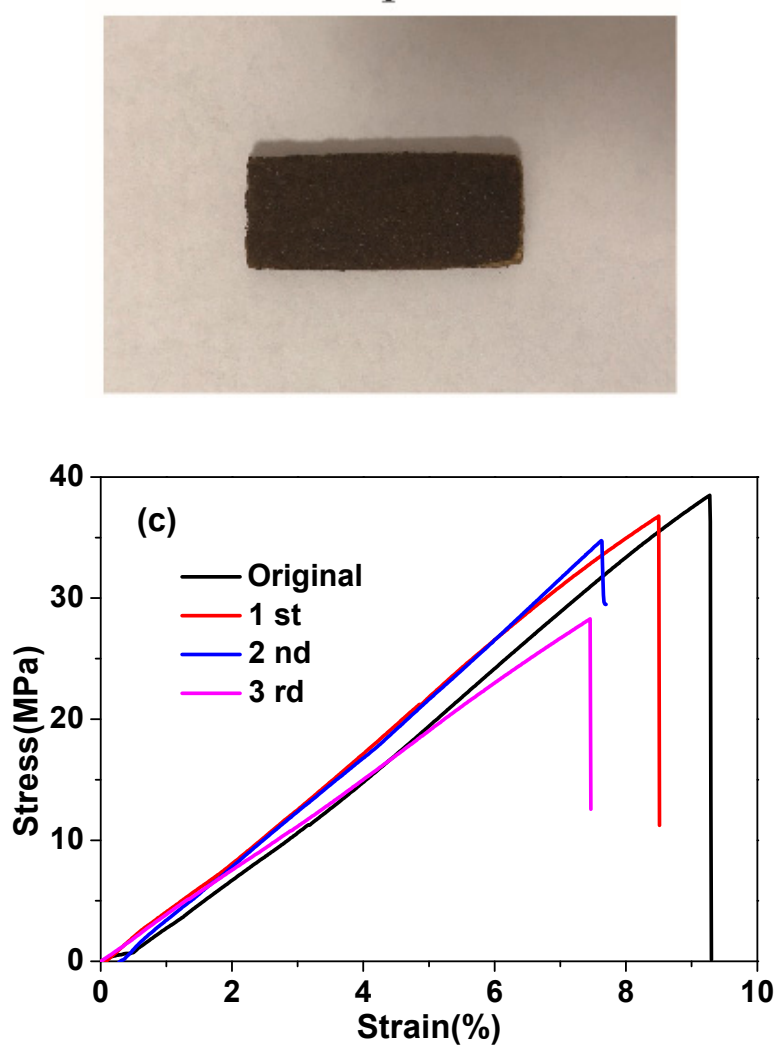
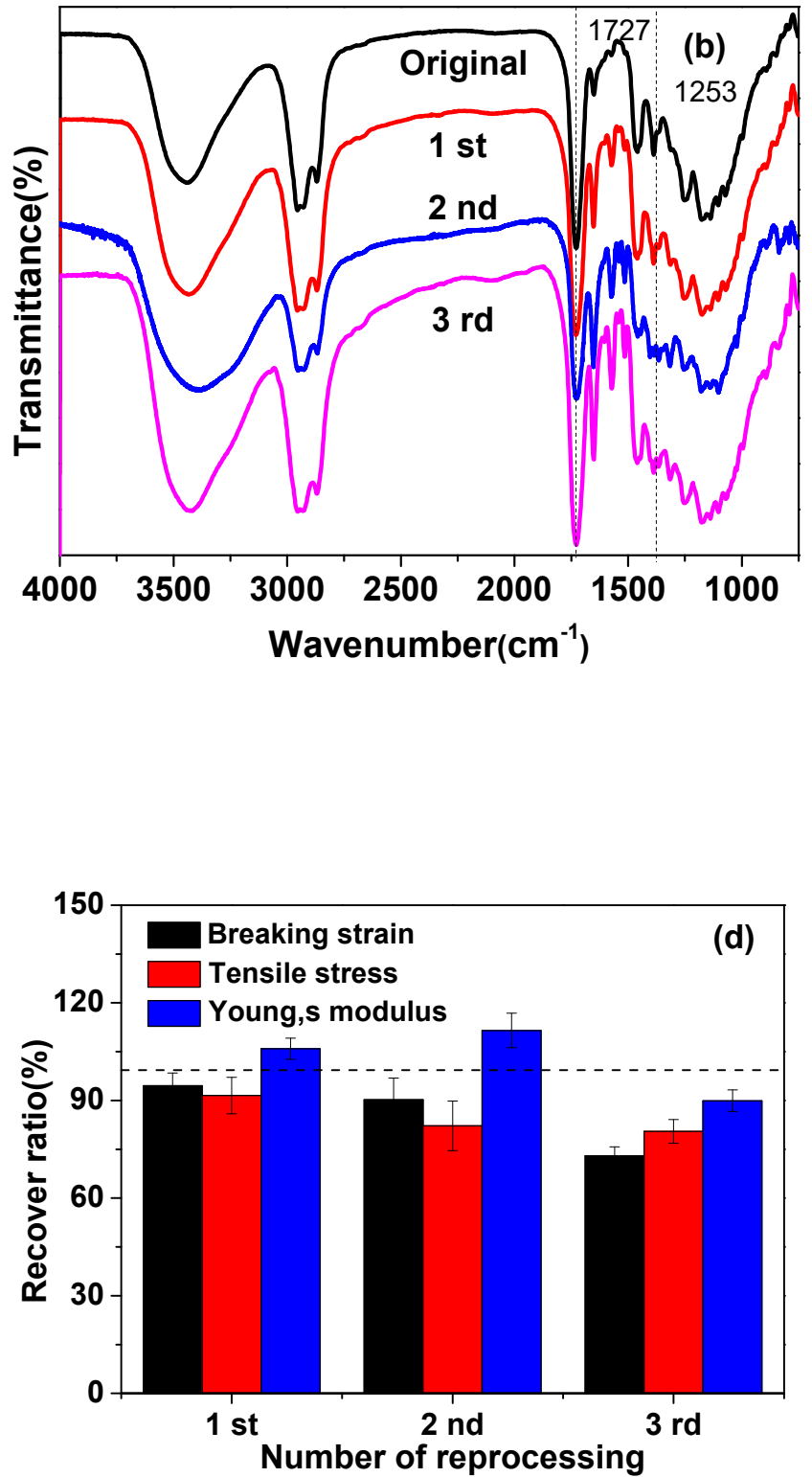

Figure 11. (a) Optical microscope images of thermal recycling performance of 20\% C-FPAE by hot press. (b) FTIR spectra of $20 \%$ C-FPAE with different generations of reprocessing. (c) Tensile curves of samples with different generations of reprocessing. (d) Recovery ratios of samples with different generations of reprocessing.

\subsection{Chemical Degradation}

Boronic ester bonds are highly sensitive to reactive oxygen species, and in acidic media with a $\mathrm{pH}$ much lower than their $\mathrm{pKa}$, boronic ester bonds are more prone to hydrolysis and cleavage into boric acid and diol (Figure 12a) [58,59]. Due to unstable boronic bond under active oxygen and acidic conditions, degradability of the rosin vitrimer is expected. Here, $20 \%$ C-FPAE powder samples were immersed in a mixed solution of THF $/ \mathrm{H}_{2} \mathrm{O}_{2} / \mathrm{HCl}$ with different $\mathrm{pH}$ at $30^{\circ} \mathrm{C}$ for $48 \mathrm{~h}$ under continuous stirring, and the degradation weight percentages of the samples were calculated (Figure $12 \mathrm{~b}$ ). With the $\mathrm{pH}$ decreasing from 6.5 to 0.0 , the degradable weight percentages increased from $10 \%$ to $90 \%$. Therefore, we can conclude that a strong acid solution is desirable for 20\% C-FPAE degradation. To 
investigate the degradation process, real-time FTIR was used, and Figure 12c shows the FTIR spectra of $20 \%$ C-FPAE at different degradation treating times $(1 \mathrm{~min}, 6 \mathrm{~h}, 12 \mathrm{~h}$, $24 \mathrm{~h}, 36 \mathrm{~h}, 48 \mathrm{~h}$ ). The absorption peaks at 1181, 1316, and $1734 \mathrm{~cm}^{-1}$ originated from the stretching vibrations of $-\mathrm{C}-\mathrm{O}-\mathrm{C}-$ in the furan group, $\mathrm{B}-\mathrm{OH}$ in the boronic acid bond, and $\mathrm{C}=\mathrm{O}$ in carbonyl, respectively [60]. As the degradation time was prolonged, the absorption of $\mathrm{B}-\mathrm{OH}$ and $\mathrm{C}=\mathrm{O}$ gradually came out and became strong in the spectra. Meanwhile, the height of different peaks during the degradation process was recoded (Figure 12d). The increased absorptions at 1316 and $1734 \mathrm{~cm}^{-1}$ indicated the increase in the $\mathrm{B}-\mathrm{OH}$ and $\mathrm{C}=\mathrm{O}$ groups in the mixture solution, with stable absorption at $1181 \mathrm{~cm}^{-1}$ as reference. These results were attributed to the breakage of unstable boronic bonds, leading to a new generation of the $\mathrm{B}-\mathrm{OH}$ group and soluble $\mathrm{C}=\mathrm{O}$ group. This work first demonstrated the possibility of using boronic ester bonds to design degradable epoxy vitrimers.
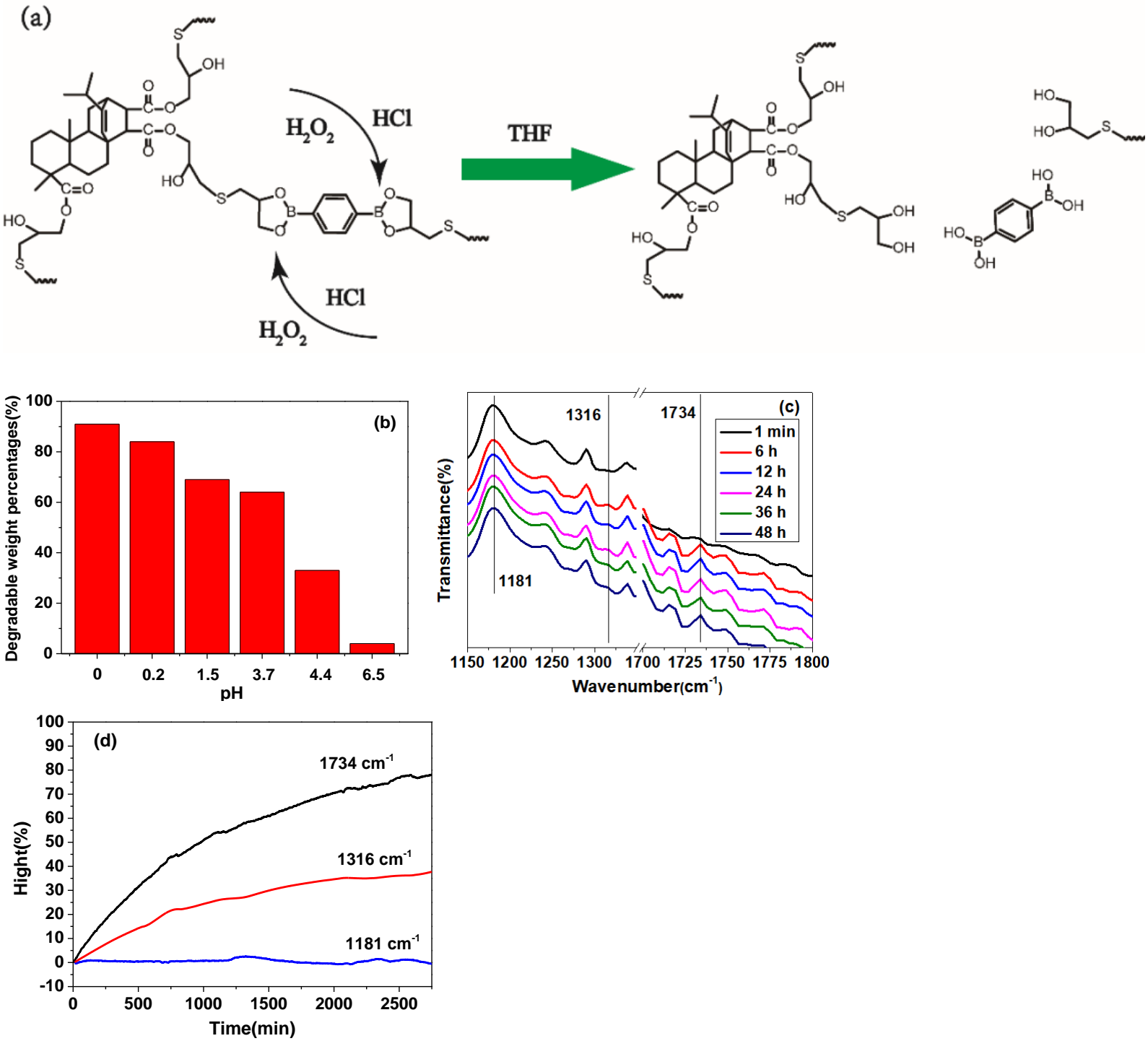

Figure 12. (a) Schematic representation of C-FPAE degradation. (b) The degradation weight percentage of 20\% C-FPAE in mixed solutions with different $\mathrm{pH}$. (c) Real-time FTIR spectra of $20 \%$ C-FPAE in mixed solution with $\mathrm{pH}=0$ for different times. (d) The height of the three characteristic peaks of FTIR (at 1734, 1316 and $1181 \mathrm{~cm}^{-1}$ ) during the degradation process. 


\section{Conclusions}

A straightforward approach was established to fabricate a mechanically robust, weldable, malleable, and recyclable epoxy vitrimer, which are based on natural rosin having dynamic reversible boronic ester bonds. The networks of the rosin-based expoy vitrimer (C-FPAE) were obtained through chemical reactions between the thiols of BDB as a curing agent and the epoxy groups of the rosin derivative as a monomer, which were identified by FTIR spectroscopy and swelling experiments. High mechanical properties with a tensile strength of $39.5 \mathrm{MPa}$, elongation at break of $9.1 \%$, and Young's modulus of $4.2 \mathrm{MPa}$ were obtained from $20 \%$ C-FPAE, and the mechanical behaviors could be regulated by changing the BDB contents from $4 \%$ to $20 \%$. C-FPAE networks with reversibly covalent cross-linkers can rearrange their topology, allowing them be healed, welded, reshaped, and recycled, because of the dynamic reversible of boronic ester bonds. Furthermore, the C-FPAE sample recovered its original mechanical properties in the range of 70 115\% after recycling. This work shows the potential of natural rosin for vitrimer network fabrication.

Supplementary Materials: The following are available online at https: / www.mdpi.com/article/ 10.3390/polym13193386/s1, Figure S1: Storage module curves; Figure S2: Tan $\delta$ curves of C-FPAE series from the DMA; Figure S3: Consecutive shape memory cycles curves of 20\% C-FPAE; Table S1: The crosslinking density and other swell parameter of the C-FPAE series with different BDB contents.

Author Contributions: Conceptualization, Y.Z.; methodology, J.L.; software, S.L.; validation, J.L. and B.Y.; formal analysis, J.L.; investigation, S.L.; resources, B.Y.; data curation, Y.Z.—original draft preparation, Y.Z.; writing-review and editing, Y.Z.; visualization, Y.Z.; supervision, Y.Z.; project administration, Y.Z.; funding acquisition. All authors have read and agreed to the published version of the manuscript.

Funding: This research was funded by Guangxi the Natural Science Foundation, grant number 2018GXNSFBA281121.

Institutional Review Board Statement: Not applicable.

Informed Consent Statement: Not applicable.

Data Availability Statement: Not applicable.

Acknowledgments: The authors acknowledgement the financial support from the Guangxi Natural Science Foundation (2018GXNSFBA281121) and Guangxi "Hundred Talents for Returned Scholars".

Conflicts of Interest: The authors declare no conflict of interest.

\section{References}

1. Raquez, J.M.; Deléglise, M.; Lacrampe, M.F.; Krawczak, P. Thermosetting (bio)materials derived from renewable resources: A critical review. Prog. Polym. Sci. 2010, 35, 487-509. [CrossRef]

2. Montarnal, D.; Capelot, M.; Tournilhac, F.; Leibler, L. Silica-Like Malleable Materials from Permanent Organic Networks. Science 2011, 334, 965-968. [CrossRef] [PubMed]

3. Denissen, W.; Winne, J.M.; Du Prez, F.E. Vitrimers: Permanent organic networks with glass-like fluidity. Chem. Sci. 2016, 7, 30-38. [CrossRef]

4. He, C.; Shi, S.; Wu, X.; Russell, T.P.; Wang, D. Atomic Force Microscopy Nanomechanical Mapping Visualizes Interfacial Broadening between Networks Due to Chemical Exchange Reactions. J. Am. Chem. Soc. 2018, 140, 6793-6796. [CrossRef] [PubMed]

5. Capelot, M.; Unterlass, M.M.; Tournilhac, F.; Leibler, L. Catalytic Control of the Vitrimer Glass Transition. ACS Macro Lett. 2012, 1, 789-792. [CrossRef]

6. Denissen, W.; Rivero, G.; Nicolaÿ, R.; Leibler, L.; Winne, J.M.; Du Prez, F.E. Vinylogous Urethane Vitrimers. Adv. Funct. Mater. 2015, 25, 2451-2457. [CrossRef]

7. Cash, J.J.; Kubo, T.; Bapat, A.P.; Sumerlin, B.S. Room-Temperature Self-Healing Polymers Based on Dynamic-Covalent Boronic Esters. Macromolecules 2015, 48, 2098-2106. [CrossRef]

8. Weegen, V.D.; Rob, N.; Renaud, A.B.; Roettger, M.; Domenech, T.; Leibler, L. High-performance vitrimers from commodity thermoplastics through dioxaborolane metathesis. Science 2017, 356, 62-65.

9. Cromwell, O.R.; Chung, J.; Guan, Z. Malleable and Self-Healing Covalent Polymer Networks through Tunable Dynamic Boronic Ester Bonds. J. Am. Chem. Soc. 2015, 137, 6492-6495. [CrossRef] 
10. Ogden, W.A.; Guan, Z. Recyclable, Strong, and Highly Malleable Thermosets Based on Boroxine Networks. J. Am. Chem. Soc. 2018, 140, 6217-6220. [CrossRef]

11. Denissen, W.; Droesbeke, M.; Nicolay, R.; Leibler, L.; Winne, J.M.; Du Prez, F.E. Chemical control of the viscoelastic properties of vinylogous urethane vitrimers. Nat. Commun. 2017, 8, 14857. [CrossRef]

12. Obadia, M.M.; Mudraboyina, B.P.; Serghei, A.; Montarnal, D.; Drockenmuller, E. Reprocessing and Recycling of Highly CrossLinked Ion-Conducting Networks through Transalkylation Exchanges of C-N Bonds. J. Am. Chem. Soc. 2015, 137, 6078-6083. [CrossRef]

13. Ishibashi, J.S.A.; Kalow, J.A. Vitrimeric Silicone Elastomers Enabled by Dynamic Meldrum's Acid-Derived Cross-Links. ACS Macro Lett. 2018, 7, 482-486. [CrossRef]

14. Geng, H.; Wang, Y.; Yu, Q.; Gu, S.; Zhou, Y.; Xu, W.; Zhang, X.; Ye, D. Vanillin-Based Polyschiff Vitrimers: Reprocessability and Chemical Recyclability. ACS Sustain. Chem. Eng. 2018, 6, 15463-15470. [CrossRef]

15. Lu, Y.X.; Guan, Z. Olefin metathesis for effective polymer healing via dynamic exchange of strong carbon-carbon double bonds. J. Am. Chem. Soc. 2012, 134, 14226-14231. [CrossRef]

16. Snyder, R.L.; Fortman, D.J.; De Hoe, G.X.; Hillmyer, M.A.; Dichtel, W.R. Reprocessable Acid-Degradable Polycarbonate Vitrimers. Macromolecules 2018, 51, 389-397. [CrossRef]

17. Bull, S.D.; Davidson, M.G.; Van, D.; Fossey, J.S.; Jenkins, A.; Jiang, Y.B.; Kubo, Y.; Marken, F.; Sakurai, K.; Zhao, J. Exploiting the reversible covalent bonding of boronic acids: Recognition, sensing, and assembly. Acc. Chem. Res. 2013, 46, 312. [CrossRef] [PubMed]

18. Deng, C.C.; Brooks, W.L.A.; Abboud, K.A.; Sumerlin, B.S. Boronic Acid-Based Hydrogels Undergo Self-Healing at Neutral and Acidic pH. ACS Macro Lett. 2015, 4, 220-224. [CrossRef]

19. Liu, X.; Xin, W.; Zhang, J. Rosin-based acid anhydrides as alternatives to petrochemical curing agents. Green Chem. 2009, 11, 1018. [CrossRef]

20. Atta, A.M.; Ramadan, A.M.; Shaffei, K.A.; Nassar, A.M.; Ahmed, N.S.; Fekry, M. Synthesis and Properties of Nonionic Surfactants from Rosin-Imides Maleic Anhydride Adduct. J. Dispers. Sci. Technol. 2009, 30, 1100-1110. [CrossRef]

21. Liu, X.; Li, C.; Zhang, D.; Xiao, Y.; Guan, G. Synthesis, characterization and properties of poly(butylene succinate) modified with rosin maleopimaric acid anhydride. Polym. Int. 2006, 55, 545-551. [CrossRef]

22. Wang, H.; Liu, X.; Liu, B.; Zhang, J.; Xian, M. Synthesis of rosin-based flexible anhydride-type curing agents and properties of the cured epoxy. Polym. Int. 2009, 58, 1435-1441. [CrossRef]

23. Liu, X.; Zhang, J. High-performance biobased epoxy derived from rosin. Polym. Int. 2010, 59, 607-609. [CrossRef]

24. Liu, X.; Xin, W.; Zhang, J. Rosin-derived imide-diacids as epoxy curing agents for enhanced performance. Bioresour. Technol. 2010, 101, 2520-2524. [CrossRef]

25. Wang, H.; Liu, B.; Liu, X.; Zhang, J.; Xian, M. Synthesis of biobased epoxy and curing agents using rosin and the study of cure reactions. Green Chem. 2008, 10, 1190. [CrossRef]

26. Ma, Q.; Liu, X.; Zhang, R.; Zhu, J.; Jiang, Y. Synthesis and properties of full bio-based thermosetting resins from rosin acid and soybean oil: The role of rosin acid derivatives. Green Chem. 2013, 15, 1300. [CrossRef]

27. Zhang, H.; Yang, Y.; Liu, H.; Song, J.; Shang, S.; Song, Z. Synthesis and bulk polymerization kinetics of monomer dehydroabietic acid-(2-acryloyloxy-ethoxy)-ethyl ester. Front. Agric. Sci. Eng. 2017, 4, 99-107. [CrossRef]

28. Yang, X.; Guo, L.; Xu, X.; Shang, S.; Liu, H. A fully bio-based epoxy vitrimer: Self-healing, triple-shape memory and reprocessing triggered by dynamic covalent bond exchange. Mater. Des. 2020, 186, 108248. [CrossRef]

29. Deng, L.; Ha, C.; Sun, C.; Zhou, B.; Yu, J.; Shen, M.; Mo, J. Properties of Bio-based Epoxy Resins from Rosin with Different Flexible Chains. Ind. Eng. Chem. Res. 2013, 52, 13233-13240. [CrossRef]

30. Zeng, Y.; Liu, S.; Xu, X.; Chen, Y.; Zhang, F. Fabrication and curing properties of o-cresol formaldehyde epoxy resin with reversible cross-links by dynamic boronic ester bonds. Polymer 2020, 211, 123116. [CrossRef]

31. Chen, Y.; Tang, Z.; Liu, Y.; Wu, S.; Guo, B. Mechanically Robust, Self-Healable, and Reprocessable Elastomers Enabled by Dynamic Dual Cross-Links. Macromolecules 2019, 52, 3805-3812. [CrossRef]

32. Croll, S.G. Application of the Flory-Rehner equation and the Griffith fracture criterion to paint stripping. J. Coat. Technol. Res. 2009, 7, 49-55. [CrossRef]

33. Rebello, N.J.; Beech, H.K.; Olsen, B.D. Adding the Effect of Topological Defects to the Flory-Rehner and Bray-Merrill Swelling Theories. ACS Macro Lett. 2021, 10, 531-537. [CrossRef]

34. Chen, Y.; Tang, Z.; Zhang, X.; Liu, Y.; Wu, S.; Guo, B. Covalently Cross-Linked Elastomers with Self-Healing and Malleable Abilities Enabled by Boronic Ester Bonds. ACS Appl. Mater. Interfaces 2018, 10, 24224-24231. [CrossRef] [PubMed]

35. Spitler, E.L.; Dichtel, W.R. Lewis acid-catalysed formation of two-dimensional phthalocyanine covalent organic frameworks. Nat. Chem. 2010, 2, 672-677. [CrossRef]

36. Ji, F.; Li, J.; Zhang, G.; Lan, W.; Sun, R.; Wong, C.-P. Alkaline monomer for mechanical enhanced and self-healing hydrogels based on dynamic borate ester bonds. Polymer 2019, 184, 121882. [CrossRef]

37. Xu, Z.; Lu, Y.; Guo, Q. Bioinspired strategy for tuning thermal stability of PVA via hydrogen-bond crosslink. Compos. Sci. Technol. 2015, 118, 16-22.

38. Wang, C.F.; Su, Y.C.; Kuo, S.W.; Huang, C.F.; Sheen, Y.C.; Chang, F.C. Low-surface-free-energy materials based on polybenzoxazines. Angew. Chem. 2006, 45, 2248-2251. [CrossRef] [PubMed] 
39. Wang, S.; Teng, N.; Dai, J.; Liu, J.; Cao, L.; Zhao, W.; Liu, X. Taking advantages of intramolecular hydrogen bonding to prepare mechanically robust and catalyst-free vitrimer. Polymer 2020, 210, 123004. [CrossRef]

40. Chen, J.; Li, F.; Luo, Y.; Shi, Y.; Ma, X.; Zhang, M.; Boukhvalov, D.W.; Luo, Z. A self-healing elastomer based on an intrinsic non-covalent cross-linking mechanism. J. Mater. Chem. A 2019, 7, 15207-15214. [CrossRef]

41. Ma, Z.; Wang, Y.; Zhu, J.; Yu, J.; Hu, Z. Bio-based epoxy vitrimers: Reprocessibility, controllable shape memory, and degradability J. Polym. Sci. Part A Polym. Chem. 2017, 55, 1790-1799. [CrossRef]

42. Yuanqin, X.; Zhuojuan, J.; Yanyan, X.; Xuyong, Z.; Weijian, X. Development of a DOPO-containing melamine epoxy hardeners and its thermal and flame-retardant properties of cured products. J. Appl. Polym. Sci. 2013, 127, 4352-4358.

43. Wang, S.; Xing, X.; Wang, W.; Jing, X. Influence of poly (dihydroxybiphenyl borate) on the curing behaviour and thermal pyrolysis mechanism of phenolic resin. Polym. Degrad. Stab. 2017, 144, 378-391. [CrossRef]

44. Yang, Y.; Peng, G.; Wu, S.; Hao, W. A repairable anhydride-epoxy system with high mechanical properties inspired by vitrimers. Polymer 2018, 159, 162-168. [CrossRef]

45. Galià, M.; de Espinosa, L.M.; Ronda, J.C.; Lligadas, G.; Cádiz, V. Vegetable oil-based thermosetting polymers. Eur. J. Lipid Sci. Technol. 2010, 112, 87-96. [CrossRef]

46. Altuna, F.I.; Pettarin, V.; Williams, R. Self-healable polymer networks based on the cross-linking of epoxidised soybean oil by an aqueous citric acid solution. Green Chem. 2013, 15, 3360-3366. [CrossRef]

47. Van Zee, N.J.; Nicolaÿ, R. Vitrimers: Permanently crosslinked polymers with dynamic network topology. Prog. Polym. Sci. 2020, 104, 101233. [CrossRef]

48. Krishnakumar, B.; Sanka, R.V.S.P.; Binder, W.H.; Parthasarthy, V.; Rana, S.; Karak, N. Vitrimers: Associative dynamic covalent adaptive networks in thermoset polymers. Chem. Eng. J. 2020, 385, 123820. [CrossRef]

49. Liu, W.X.; Zhang, C.; Zhang, H.; Zhao, N.; Yu, Z.X.; Xu, J. Oxime-Based and Catalyst-Free Dynamic Covalent Polyurethanes. J. Am. Chem. Soc. 2017, 139, 8678-8684. [CrossRef]

50. Wu, X.; Yang, X.; Yu, R.; Zhao, X.; Zhang, Y. A facile access to stiff epoxy vitrimers with excellent mechanical properties via siloxane equilibration. J. Mater. Chem. A Mater. Energy Sustain. 2018, 6, 10184-10188. [CrossRef]

51. Yang, F.; Pan, L.; Ma, Z.; Lou, Y.; Li, Y.; Li, Y. Highly elastic, strong, and reprocessable cross-linked polyolefin elastomers enabled by boronic ester bonds. Polym. Chem. 2020, 11, 3285-3295. [CrossRef]

52. Xiong, X.; Guo, X.; Ren, R.; Zhou, L.; Chen, P. A novel multifunctional glycidylamine epoxy resin containing phthalide cardo structure: Synthesis, curing kinetics and dynamic mechanical analysis. Polym. Test. 2019, 77, 105917. [CrossRef]

53. Dumlu, H.; Marquardt, A.; Zirdehi, E.M.; Varnik, F.; Shen, Y.; Neuking, K.; Eggeler, G. A Mechanical Analysis of Chemically Stimulated Linear Shape Memory Polymer Actuation. Materials 2021, 14, 481. [CrossRef]

54. Devangamath, S.S.; Lobo, B.; Masti, S.P.; Narasagoudr, S. Mechanical and Dynamic Mechanical Studies on Epoxy-Cobaltous Sulfate Polymer Hybrids. Fibers Polym. 2018, 19, 1490-1499. [CrossRef]

55. Liu, T.; Hao, C.; Wang, L.; Li, Y.; Liu, W.; Xin, J.; Zhang, J. Eugenol-Derived Biobased Epoxy: Shape Memory, Repairing, and Recyclability. Macromolecules 2017, 50, 8588-8597. [CrossRef]

56. Pei, Z.; Yang, Y.; Chen, Q.; Terentjev, E.M.; Wei, Y.; Ji, Y. Mouldable liquid-crystalline elastomer actuators with exchangeable covalent bonds. Nat. Mater. 2014, 13, 36-41. [CrossRef]

57. Wang, T.X.; Chen, H.M.; Salvekar, A.V.; Lim, J.; Chen, Y.; Xiao, R.; Huang, W.M. Vitrimer-Like Shape Memory Polymers: Characterization and Applications in Reshaping and Manufacturing. Polymers 2020, 12, 2330. [CrossRef] [PubMed]

58. Ma, R.; Shi, L. Phenylboronic acid-based glucose-responsive polymeric nanoparticles: Synthesis and applications in drug delivery. Polym. Chem. 2014, 5, 1503-1518. [CrossRef]

59. Bosch, L.I.; Fyles, T.M.; James, T.D. Binary and ternary phenylboronic acid complexes with saccharides and Lewis bases. Tetrahedron 2004, 60, 11175-11190. [CrossRef]

60. Lambert, J.B.; Shurvell, H.F.; Lightner, D.A.; Cooks, R.G. Introduction to Organic Spectroscopy; Macmillan Publishing Company: New York, NY, USA, 1987. 